\title{
EXPLORING THE LIVED EXPERIENCE OF THE SOCIAL ABCs PARENT-MEDIATED INTERVENTION STUDY
}

\author{
by \\ Melanie Elizabeth Fenwick \\ Bachelor of Arts, McGill University, Montreal, Quebec 2008
}

\author{
A Major Research Paper \\ Presented to Ryerson University \\ in partial fulfillment \\ of the requirements for the degree of \\ Master of Arts \\ in the Program of \\ Early Childhood Studies \\ Toronto, Ontario, Canada 2013 \\ (C) Melanie Elizabeth Fenwick 2013
}




\section{Author's Declaration}

I hereby declare that I am the sole author of this MRP. This is a true copy of the MRP, including any required final revisions.

I authorize Ryerson University to lend this MRP to other institutions or individuals for the purpose of scholarly research.

I further authorize Ryerson University to reproduce this MRP by photocopying or by other means, in total or in part, at the request of other institutions or individuals for the purpose of scholarly research.

I understand that my MRP may be made electronically available to the public. 


\title{
EXPLORING THE LIVED EXPERIENCE OF THE SOCIAL ABCs \\ PARENT-MEDIATED INTERVENTION STUDY
}

(C) Melanie Elizabeth Fenwick 2013

Master of Arts

in the Program of

Early Childhood Studies

\begin{abstract}
In light of the paucity of research investigating the impact on the family of parentinclusive models of intervention for young children with Autism Spectrum Disorder (ASD), this study explored the lived experience of families involved in the Social ABCs parent-mediated intervention for toddlers with ASD. Influenced by phenomenological inquiry, semi-structured interviews were conducted with seven parents from six families. Parents were asked a range of broad open-ended questions, some of which were guided by the literature on family outcomes of early intervention for children with disabilities. Using thematic analysis, the findings revealed several themes that highlighted the impact of the Social ABCs intervention on the child, the parent, and the family as a system. Five themes are discussed as they provide insight into the lived experience of families involved in the intervention: impact on child, impact on parents, impact on the family system, feasibility of implementation, and reflections on the Social ABCs experience. These findings may be useful for informing practice, policy and program development related to early intervention for young children with ASD and their families. Key Words:
\end{abstract}

Autism spectrum disorders, early intervention, parent-mediated, lived experience, family impact 


\section{Acknowledgments}

First, and most importantly, I would like to thank the families who opened up their hearts to share their experience in the Social ABCs with me. I greatly appreciate your generosity.

I would like to express my sincerest gratitude to Dr. Jessica Brian. Jess, this study would not have been possible without you, and I am so appreciative that you were willing to pursue this journey with me. I have learned so much from your guidance and support. I am truly grateful.

I would like to thank my committee members, Drs. Kathryn Underwood, Mehru Ali, and Rachel Berman for their guidance and feedback. Kathryn, your support and expertise throughout this process have been incredibly helpful and I can't thank you enough for being more to me than a second reader.

I would like to thank my mom, dad and Linda for always believing in me and never letting me give up on my dreams. Your encouragement, support and love have been a constant throughout my life that have meant more to me than you'll ever know. Love you, forever and always.

I would like to thank my big sister Robyne for teaching me to see the positive in (almost) every situation. You've been my biggest cheerleader and I'm so grateful to have you by my side.

To my friends, you have been through the ups and downs of this experience with me before it even began. Thank you for supporting me and reminding me that there is more to life than just school. To my best friend Aaron, I can't imagine my life without you in it. Thank you for never giving up on me, and of course, for always making me laugh, especially when I needed it most.

To my ATN family, thank you for your support and encouragement these last few years. I will always be thankful for being part of, working with, and learning from, such an amazing team.

To my MAECS friends, this year would not have been the same without each and every one of you, and I feel so lucky to have shared this experience with you. A special shout out to four special ladies, Jess, Cassie, Kristi and Connie... this year would not have been nearly as entertaining or memorable without each of you... in only one short year, we have embraced the good (a lot of good!), endured the bad, and overcome the ugly, and I want to thank you for being there with me through it all. This program was just the beginning... and I can't wait to see what the future holds for all of us! 


\section{Dedication}

I dedicate this paper to the children and families I have worked with over the years.

You inspire me. I am forever grateful. 


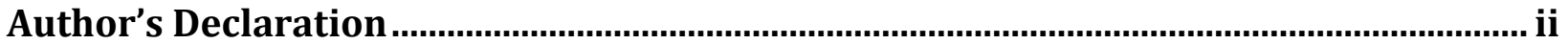

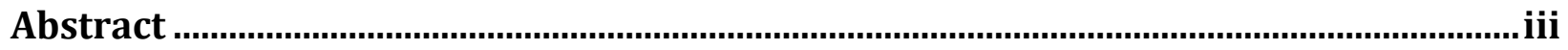

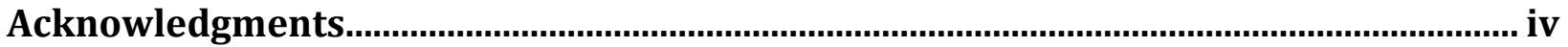

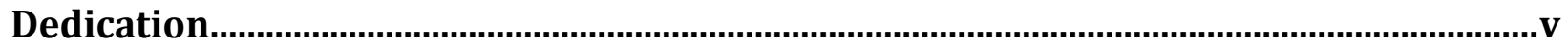

Chapter One: Introduction

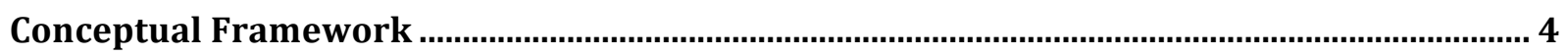

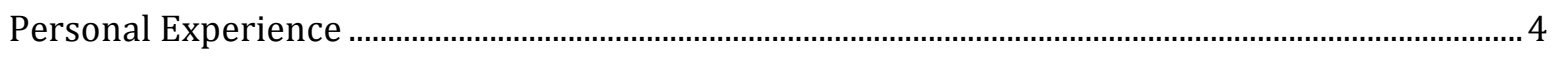

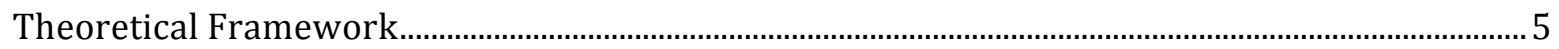

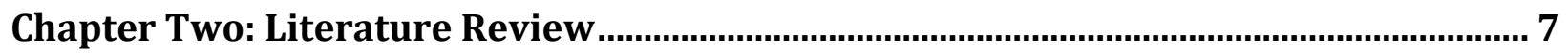

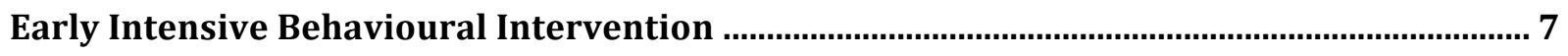

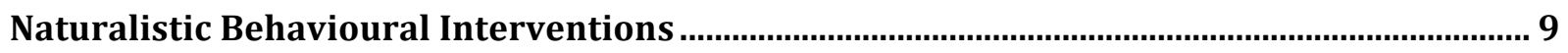

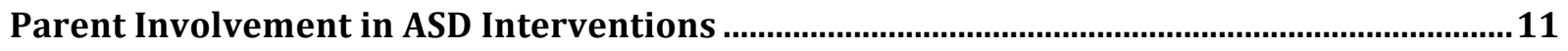

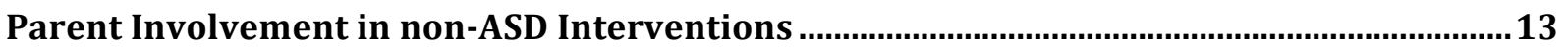

Evaluation of Family Outcomes in Parent-Inclusive ASD Interventions...................................13

Lived Experience of Families in ASD-Related Early Intervention Programs...........................15

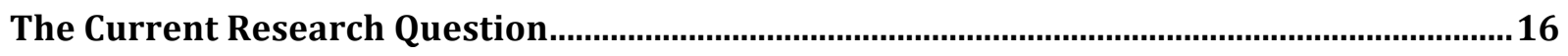

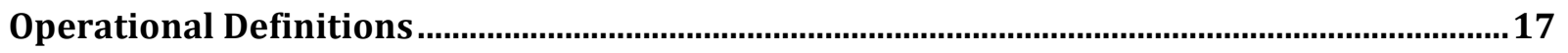

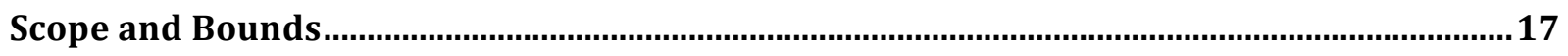

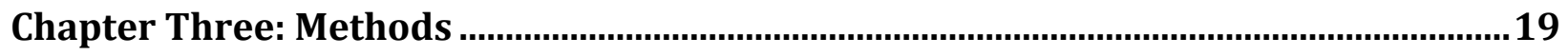

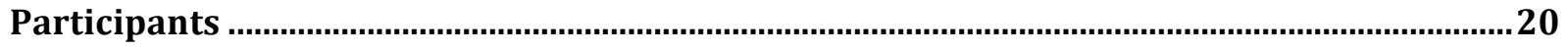

Procedure 


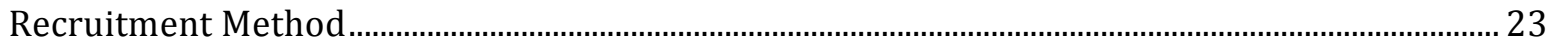

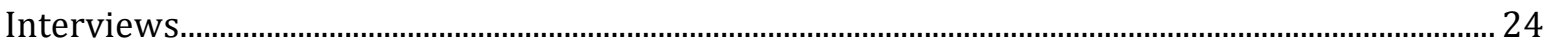

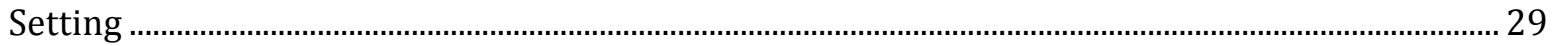

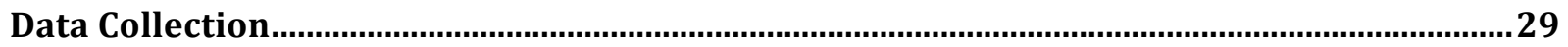

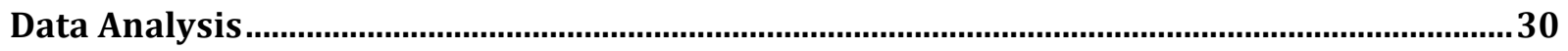

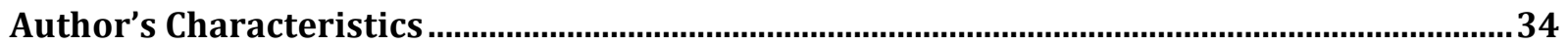

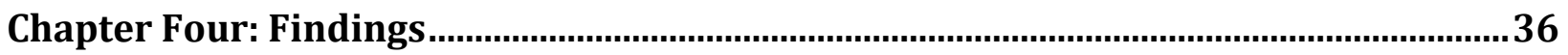

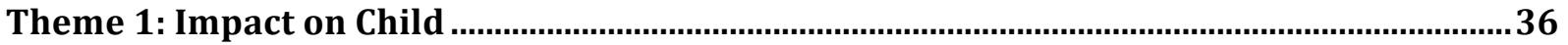

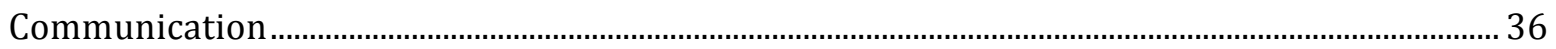

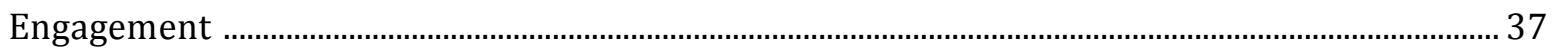

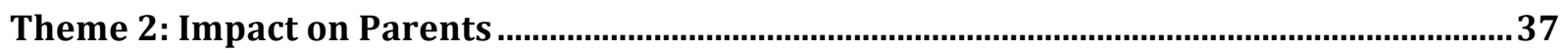

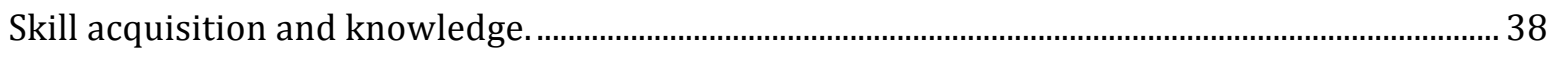

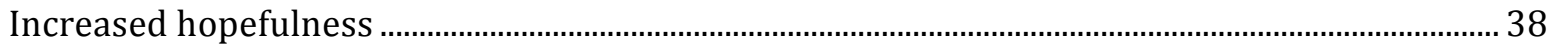

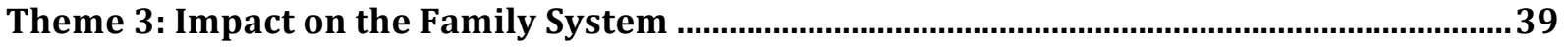

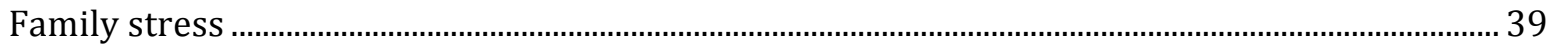

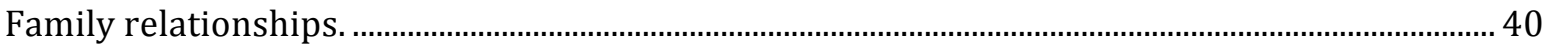

Family accommodations to daily routines.

Theme 4: Feasibility of Social ABCs Implementation ........................................................47

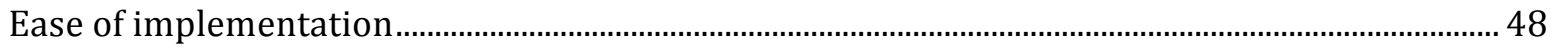

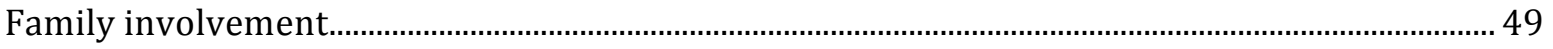

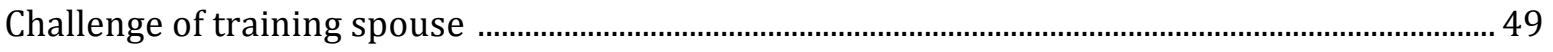

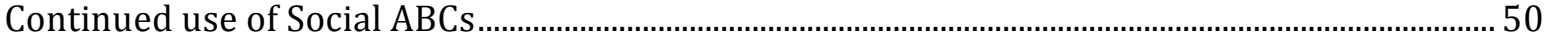

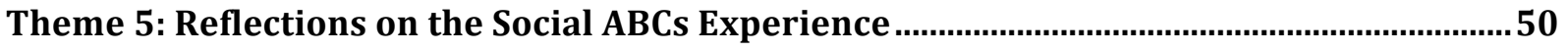

Feedback about the Social ABCs intervention model ............................................................................. 50

Positive feelings about participation in Social ABCs.............................................................................. 51 


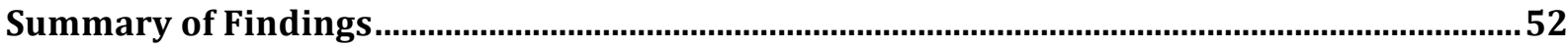

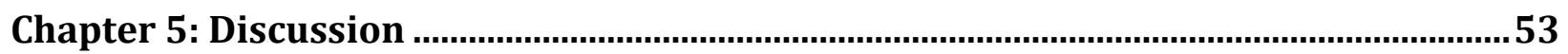

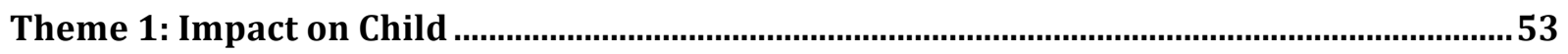

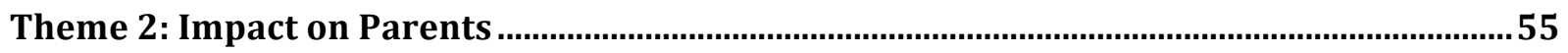

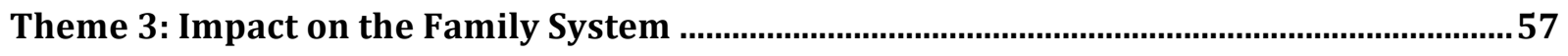

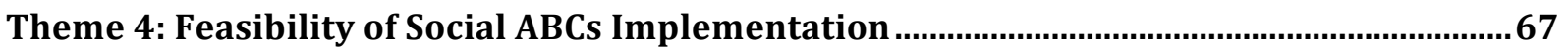

Theme 5: Reflections on the Social ABCs Experience ........................................................... 70

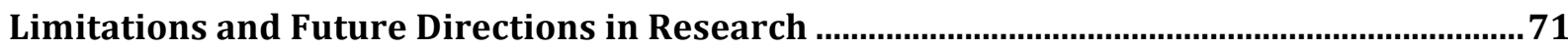

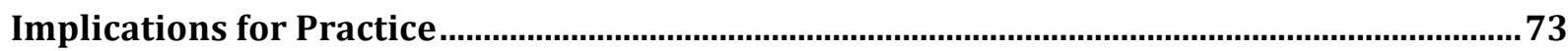

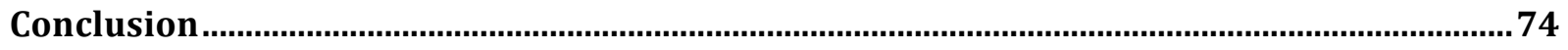

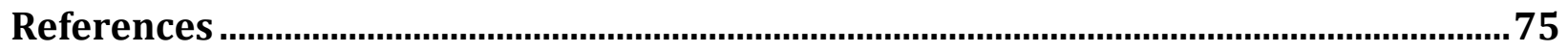

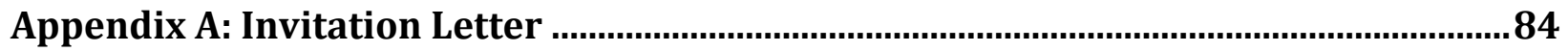

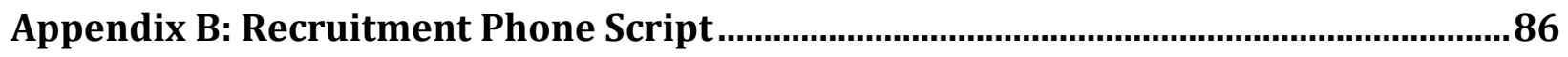

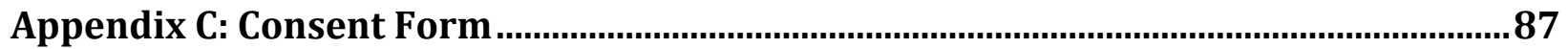

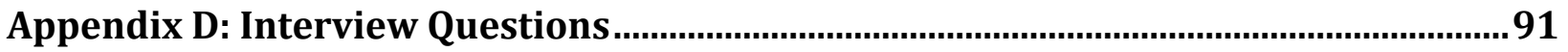




\section{Chapter One: Introduction}

The primary objective of the current study was to explore the lived experience of families involved in the Social ABCs research study for toddlers with Autism Spectrum Disorder (ASD). The Social ABCs is a parent-mediated intervention that employs the evidence-based fundamentals of Applied Behaviour Analysis (ABA) in the form of Pivotal Response Treatment (PRT), with adaptations made for the toddler age group. PRT relies on children's motivation for objects to develop speech and social skills in natural settings (e.g., in their home with parents). The intervention is taught to parents in their homes and targets two areas of early impairment in ASD: positive emotion sharing and functional speech. The Social ABCs research study was conducted as a randomized controlled trial, with the Social ABCs experimental group receiving six months of intervention (i.e., three months of parent training followed by three months of parent implementation and follow up), and the control group receiving six months of waitlist, followed by six months of Social ABCs intervention, if parents were interested. With the goal of exploring families' lived experience of the Social ABCs intervention, the current study was guided by phenomenological inquiry. All families who had completed the Social ABCs intervention were invited to participate in semi-structured interviews, and themes were identified to provide insight into the lived experience of the Social ABCs for families who participated in the current study.

Autism Spectrum Disorders (ASD) are the fastest growing neurodevelopmental disorders, impacting as many as one in 88 children and their families (Centers for Disease Control and Prevention, 2012). According to the Diagnostic and Statistical Manual of Mental Disorders (DSM-5; American Psychiatric Association, 2013), the term Autism Spectrum Disorder (ASD) refers to a neurodevelopmental condition that is characterized by impairments in social 
communication and social interaction, as well as the presence of restricted and repetitive behaviours and interests (RRBs). RRBs are defined as unusual maladaptive behaviours, such as strict adherence to nonfunctional routines/rituals or a persistent preoccupation with parts of an object, that are not usually seen in typically developing children (Chawarska, Klin, \& Volkmar, 2008). While severity and symptoms vary from one child to the next, ASD is typically a life-long disorder that emerges early in development and is pervasive in nature, impacting not only the diagnosed child, but also parents, caregivers, siblings, teachers and the community (Karst \& Van Hecke, 2012). Compared to parents of typically developing children and parents of children with other developmental disorders, evidence has emerged to show that parents of children with ASD typically experience greater parental and familial challenges, such as decreased experience of parental self-efficacy, increased parenting stress, decreased parental well-being, increased health concerns, increased financial strain, high rates of divorce, and lower overall quality of life (Karst \& Van Hecke, 2012). The substantial impact of ASD on the child, parents and family, combined with the increasing prevalence of the disorder, reflects a substantial challenge for the education and health care systems, and for social services (Smith et al., 2010). Therefore, it is undeniable that across multiple fields, Autism Spectrum Disorder represents an urgent priority that deserves research and clinical attention to improve the lives of children and families affected by ASD.

Intervention for individuals with ASD most commonly takes the form of teaching to skill deficits using the principles of Applied Behaviour Analysis (ABA), which involves systematic analysis and teaching of skills. ABA, particularly when implemented early and intensively (often called Early Intensive Behavioural Intervention; EIBI) has been proven effective at producing positive outcomes for children with ASD (Eldevik et al., 2009; Reichow, 2012), thus gaining recognition as "an intervention of choice for children with autism" (Eldevik et al., 2009, p. 449). 
The vast majority of EIBI programs rely heavily or exclusively on therapist- or specialistdelivered models. However, research has identified parent involvement as an important component of effective interventions for children with ASD, highlighting that treatment efficacy improves when parents are involved (McConachie \& Diggle 2007; Burrell \& Borrego, 2012; Karst \& Van Hecke, 2012). With empirical support for parent involvement in ASD interventions, researchers have highlighted how this involvement has the potential to not only benefit child outcomes, but also positively impact parent and family outcomes (Burrell \& Borrego, 2012; Karst \& Van Hecke, 2012). While parent outcomes have received increasing attention in studies evaluating ASD interventions that have a parent-training or parent-delivery component (hereafter referred to collectively as 'parent-inclusive' interventions), consideration of the impact of parents' involvement on the family by assessing family outcomes is limited (Karst \& Van Hecke, 2012). From this line of inquiry, the current study proposes to explore the lived experience of families who have participated in a parent-mediated intervention for young children with ASD (the Social ABCs; Brian et al., 2012) for the purpose of identifying family impact. Therefore, the proposed research question is: What is the lived experience of families involved in the Social ABCs parent-mediated intervention? 


\section{Conceptual Framework}

Personal Experience. Over the past five years, I have worked in research and clinical settings with a number of frustrated families who were either denied or experienced delays in access to provincially funded evidence-based interventions for their child with ASD, which in many cases resulted in feelings of lost hope. While professionals, researchers and the media emphasize the importance of early intervention as the best predictor of successful developmental outcomes, families often have limited access to feasible and affordable early intervention options that are proven effective at supporting their child. Despite the evidence to support the inclusion of parents in interventions for children with ASD, the provincially funded intervention program in Ontario (Intensive Behavioural Intervention; IBI) does not typically include parent involvement, parent training, or parent education. For these reasons, the inclusion of parents in the intervention process has been especially important to me. By providing parents with the necessary knowledge and skills to implement evidence-based interventions, we can relieve some of the inequities inherent in our current system, so that every child can receive early intervention services. It is my belief that training and educating parents in evidence-based practices will increase their confidence and competence, and in turn, decrease their feelings of inadequacy and helplessness when parenting a child with ASD. It is my ideological commitment that this research will inform future government-funded research, programs and policies to meet the urgent need for accessible, feasible, and affordable evidence-based intervention options to meet the needs of all children with ASD and their families. Inclusion of parents in the intervention process may not only improve access to intervention, but may have a positive impact on family outcomes more broadly (Burrell \& Borrego, 2012). 
Theoretical Framework. To explore the lived experience of families involved in the Social ABCs parent-mediated intervention with the purpose of gaining insight into the impact of the Social ABCs on the family, this study was influenced by ecological theory and family systems theory. These theories are used to highlight the relevance of my research to the broader discourse, and to explain the development of my research question and design.

Ecological Theory. Bronfenbrenner's (1986) ecological theory highlights the influential role of parents on children's development. According to this theory, the family serves as the most important context in which human development occurs. The microsystem, one of four systems that comprise the ecological model, is the environment closest to the child, that encompasses the family. The interactions between the child and his/her environments within the microsystem are viewed as two-directional and reciprocal, suggesting that the parent not only impacts the child, but that in turn, the child impacts the parent (Gardiner \& Kosmitzki, 2011). This is an important underlying theoretical assumption for the current investigation.

Family Systems Theory. At the heart of family systems theory is the assumption that the family is a system that can only be understood in its entirety, as it is composed of interconnected parts (individual members) that influence one another reciprocally (White \& Klein, 2002). Therefore, not only does the family impact the child's development and behaviour, but in turn, the child impacts the functioning of the family as a whole. With regard to families of children with disabilities, Turnbull and Turnbull (1990) argue that the dynamics of a family are especially impacted when a child has a disability. The characteristics of the individual, of each family member, and of the family as a whole, are important to understanding the impact of a child's disability on the family. In light of this theoretical position, greater "consideration must be given to the family system in planning interventions with autistic children" (Morgan, 1988, p. 264). 
From this brief illustration of ecological theory and family systems theory, it is evident that this research is relevant to the broader discourse. The ecological and family systems theories highlight the importance of reciprocal influences within the family on developmental outcomes. This exploration into the lived experience of families in the Social ABCs intervention aims to explore the impact of parent involvement in an ASD intervention on the family as a system, with an emphasis on family stress, family functioning and family accommodations. It is expected, according to these theoretical perspectives, that the impact of the intervention will extend not only to the child and parent, but also to the larger family system. Building from the foundation of this combined theoretical framework, the current study aims to gain insight into the lived experience of families involved in the Social ABCs parent-mediated intervention for toddlers with Autism Spectrum Disorder. 


\section{Chapter Two: Literature Review}

The literature was reviewed with the purpose of determining the following: the state of knowledge about early intensive behavioural intervention; the emergence of naturalistic behavioural interventions; the evidence to support the inclusion of parents in interventions for children with and without ASD; the impact of parent involvement in interventions for children with ASD on family outcomes; and the lived experience of families involved in ASD-related parent-inclusive interventions. The purpose of this review is to provide a rationale for this exploration and to highlight the gaps in the existing literature that will be addressed by the current investigation.

\section{Early Intensive Behavioural Intervention}

Early detection and diagnosis of ASD have been profoundly influenced by our increasing knowledge of early development in children later diagnosed with ASD (Chawarska et al., 2008; Zwaigenbaum et al., 2012). The importance of early identification has been highlighted by research showing that early intensive behavioural intervention (EIBI), based on the principles of applied behaviour analysis (ABA), is associated with positive outcomes for children with ASD. In a meta-analysis of 34 studies investigating the effects of EIBI on children's intelligence and adaptive behaviour, the average effect sizes were 1.10 and .66 respectively, highlighting the significant impact of EIBI on child outcomes (Eldevik et al., 2009). According to a recent review of 5 meta-analyses of EIBI, Reichow (2012) concluded that EIBI is a "comprehensive treatment model for individuals with ASDs with the greatest amount of empirical support" (p. 518).

The earliest research to demonstrate an improvement in child outcomes using behavioural teaching methods was Lovaas' (1987) renowned study that used discrete trial training (DTT, a primary application of EIBI) to facilitate language learning in preschool-aged children. His 
findings demonstrated that close to $50 \%$ of the 19 participants who received one-to-one DTT for up to 40 hours per week for 2-4 years or more had "recovered" by first grade, which was defined as having attained classroom placements in regular grade one programs (Lovaas, 1987).

Although Lovaas' study received substantial criticism for its methodological limitations (Chawarska et al., 2008), the efficacy of discrete trial training has been highlighted by more recent studies that replicated similar findings in randomized controlled trials (Smith, 2010). For example, Sallows and Graupner (2005) replicated Lovaas' findings, demonstrating increases in IQ scores, language, and adaptive functioning for $50 \%$ of the children who received DTT. Evidence of the benefits for children with ASD receiving early intensive behavioural treatment, grounded in ABA, has led to the widespread implementation of provincially funded early intensive behavioural intervention (EIBI) programs across Canada (Smith et al., 2010).

Within the last decade, considerable controversy has challenged the perception of the Lovaas model as the only treatment method to produce significant developmental outcomes for children with ASD. First, child outcomes are considerably variable with DTT (only $50 \%$ of children show benefits), suggesting that this form of intervention may not be the best fit for all children with ASD (Chawarska et al., 2008). This finding has important implications for examining alternative behavioural approaches to meet the needs of the $50 \%$ of children who do not respond positively to DTT. Second, children's lack of generalization of learning and limited social initiations, reliance on specific prompts and reinforcers that are artificially related to the learning task, and unknown maintenance of treatment effects, all contribute to concerns with the DTT model (Chawarska et al., 2008). Traditionally, DTT is conducted on a one-to-one basis between the therapist and the child, where skills or behaviours are broken down into smaller steps to facilitate learning. For the most part, table top work is used to teach cognitive, language, 
social and self-help skills that are mostly reinforced with unrelated items (e.g., 'artificial reinforcers' such as food treats). Moreover, traditional DTT models tend not to address the initiation of social interactions with peers, and teaching these skills in alternative environments is not emphasized. Third, the cost required to provide this treatment, approximately $\$ 40,000$ per child per year, is relatively high and often unfeasible for families when not publicly available (Chasson et al., 2007), and it is a considerable drain on the social services/public health system where it is provided publicly. Fourth, with the dramatic increase in the number of children diagnosed with ASD over the past three decades (Karst \& Van Hecke, 2012), there is an overwhelming demand on service providers to increase the availability and accessibility of EIBI. Consequently, many children are precluded from or encounter delays in access to intervention due to long waiting lists (Coolican, Smith \& Bryson, 2010). Although parents can access private forms of therapy to maximize their child's learning while waitlisted for publicly funded programs, the costs are too high for most families. Finally, intensive behavioural intervention can be stressful and time consuming for families, as it is recommended that children receive 30-40 hours per week for 2-4 years to achieve improved outcomes (Chawarska et al., 2008). It is important to consider the unique needs of the child and the family in order to select an intervention that is a good fit for both, and yet this is rarely done in current practice.

\section{Naturalistic Behavioural Interventions}

To address the methodological and theoretical limitations and challenges with the traditional DTT approach, a shift towards more naturalistic behavioural interventions has emerged. A strong body of research has supported the implementation of ABA principles in what are typically referred to as "natural" settings (e.g., the child's home, school, with peers and parents) to facilitate more functional learning for children with ASD (Landry, Smith \& Swank, 
2006; Bryson et al., 2007; McConachie \& Diggle, 2007; Smith et al., 2010; Coolican et al., 2010; Burrell \& Borrego, 2012; Karst \& Van Hecke, 2012). Naturalistic behavioural approaches emphasize teaching that is child-initiated and focused on the child's interests, embedded in functional activities, and that relies on natural reinforcers to follow the child's efforts to communicate (Chawarska et al., 2008). Natural reinforcers are items (e.g., snacks, toys, games, activities) of interest to the child that are related to the response that is being elicited, and are distinguished from "artificial" or "contrived" reinforcers which are arbitrarily chosen items that are not naturally related to the activity. Examples of naturalistic behavioural interventions include incidental teaching and Pivotal Response Treatment (Koegel et al., 1999a; Landry et al., 2008).

One naturalistic method that has received significant recognition for its focus on targeting communication using a naturalistic child-directed intervention is Pivotal Response Treatment (PRT) (Koegel et al., 1999). One of the fundamental goals of PRT is to increase the child's motivation to communicate and interact with his/her parents or caregivers, by promoting child choice, task variation and immediate natural reinforcers. This model allows multiple caregivers to implement the intervention in natural settings, thus promoting spontaneity, generalization, and maintenance of treatment outcomes across environments and people, a challenge of traditional discrete trial teaching methods. In addition to the large body of research demonstrating the efficacy of PRT for young children with ASD (Koegel et al., 1999a; Bryson et al., 2007; McConachie \& Diggle, 2007; Smith et al., 2010; Coolican et al., 2010), PRT emphasizes the inclusion of parent training and education in the intervention process, which has been linked to positive changes in children's communication (functional speech) and parents' affect (Chawarska et al., 2008; McConachie \& Diggle, 2007). 


\section{Parent Involvement in ASD Interventions}

With the emergence of more naturalistic approaches to early behavioural intervention, together with evidence that generalization and maintenance of skills are reduced with traditional DTT approaches, the role of parent involvement in naturalistic ASD interventions has received increasing attention (Burrell \& Borrego, 2012). Lovaas' (1987) early work was one of the first to demonstrate the impact of parent training, such that children of parents who were trained in the intervention showed continued improvement following clinic treatment, whereas children whose parents were not trained deteriorated. Training parents and increasing their skills allows for continual opportunities to maximize children's learning in multiple naturally occurring situations. In 2007, McConachie and Diggle conducted a systematic review of parentimplemented early intervention programs for young children with ASD. At that time, few randomized controlled trials were available to determine the effectiveness of parent training compared to intervention as usual (no parent training). Nonetheless, McConachie and Diggle (2007) concluded that parent training can successfully contribute to interventions for children with ASD, highlighting improvements in child communicative behaviour, increased maternal knowledge of autism, enhanced maternal communication style, enhanced parent-child interaction, and reduced maternal depression.

Although this area has been primarily dominated by quantitative investigations, some studies have included a complimentary qualitative component to obtain parents' perceptions of parent-inclusive EIBI programs. For example, McConkey and colleagues (2010) conducted semi-structured interviews with parents to gain their perceptions of a home-based program intended to promote communication in young children with ASD. A thematic analysis revealed that all mothers expressed that their child had benefited from the program by learning new skills, 
and $91 \%$ of the mothers reported that the family as a whole had benefited. Parents highlighted the knowledge, emotional support and advice provided through the program, and $88 \%$ of mothers expressed a change in their attitude toward their child, such that they became more understanding of their child's difficulties. While this study is a first step toward gaining the perspectives of individuals to better understand the impact of the intervention on the family, very few entirely qualitative studies of parents' experiences and perceptions of parent-inclusive ASD specific interventions exist.

Recently, training programs for parents of children with ASD have grown considerably in response to the evidence that direct parent training leads to success in the extent to which parents learn effective and appropriate intervention techniques and acquire increased knowledge regarding ASD (Karst \& Van Hecke, 2012). Parent training programs for children with ASD have primarily focused on improving children's language and social communication skills (Schertz \& Odom, 2006; Dawson et al., 2009; Oosterling et al., 2010; Roberts et al., 2011; Fava et al., 2011). Research has demonstrated that parent-based interventions can enhance generalization of learning and maintenance of treatment effects across the child's daily routines (Chawarska et al., 2008). In addition, when compared with the traditional behavioural intervention model, parent-inclusive interventions tend to be more cost-effective, more accessible, more continuous, and more feasible in natural settings (White, 2011). The importance of parent training and family involvement was highlighted by The National Research Council (2001) "as one of the crucial active ingredients in effective treatment programs for children with ASD” (Chawarska et al., 2008, p. 227). 


\section{Parent Involvement in non-ASD Interventions}

Further support for the inclusion of parents in intervention programs comes from a broad range of child and adolescent disorders, including anxiety disorders, sleep, and feeding problems (Kaslow et al., 2012). However, the majority of the parent training research has focused on children with disruptive behaviour disorders or substance-related disorders. According to Kaslow et al., (2012) "outcomes are most positive when parents are engaged in the treatment" (p. 82). Positive outcomes include decreases in parent mental health concerns, increased understanding of the child's diagnosis and difficulties, improved parent-child interaction, and improvement on child outcomes in communication and social behaviour (Karst \& Van Hecke, 2012).

\section{Evaluation of Family Outcomes in Parent-Inclusive ASD Interventions}

While a considerable body of research exists to demonstrate improved child outcomes of interventions with a parent component for children with ASD (Smith et al., 2010; Coolican et al., 2010; Fava et al., 2011; Strauss et al., 2012), a focus on the impact of these interventions on parent outcomes has recently emerged (Karst \& Van Hecke, 2012). Of the twelve studies included in McConachie and Diggle's (2007) systematic review of parent implemented early interventions for young children with ASD, only six assessed the impact on parents, with parental stress being the most common measure of parental outcomes. Since then, the majority of studies assessing the impact of parent-inclusive intervention models on parents have included diverse outcome measures including parent stress, parental satisfaction with the treatment, parental perceptions of children's progress, parental self-efficacy, and parents' fidelity in implementing an intervention (Smith et al., 2010; Coolican et al., 2010; Fava et al., 2011; Strauss et al., 2012). While child and parent outcomes have been investigated as important indices of treatment impact, outcomes for the family as a whole have mostly been overlooked. It is 
important to recognize that ASD interventions, especially approaches that train and educate parents to implement the intervention, have the potential to affect the functioning, well-being, and quality of life of the family as a whole (Burrell \& Borrego, 2012). Although a variety of quantitative measures of family outcomes exist in the literature, few studies have evaluated the impact of parent-inclusive ASD interventions on the family to the same degree as parents and children (Karst \& Van Hecke, 2012). Bendixen et al., (2011), however, is a noteworthy exception that examined the impact of a father-based parent training early intervention program on parents' perceived stress and family functioning. The novel contribution made by Bixden et al. is the use of the Family Adaptability and Cohesion Evaluation Scales II (FACESII) to assess family functioning before and after the parent training intervention. Although results indicated that there were no significant differences in fathers' or mothers' scores on the FACESII following intervention, family functioning is nonetheless important to assess given the potentially influential role that parent training can have on the family system. While using the FACESII scale to assess family functioning is a strength of this study, it is also a weakness, as relying solely on quantitative data in the evaluation of an individual's or family's experience in early intervention limits "what can be learned about the meanings participants give to events" (Sandelowski, 2000, p. 336).

In contrast to the dominant quantitative approach to examining outcomes of treatment, some studies have adopted a qualitative design to investigate family experiences of parentinclusive interventions for children with ASD (Williams \& Wishart, 2007; Trudgeon \& Carr, 2007). Williams and Wishart (2003) investigated family experiences of the Son-Rise parentimplemented intervention program for children with ASD. Families completed three separate questionnaires over a one-year period (the same family member completed all forms) that 
provided information regarding parents' perceptions of the impact of their involvement in the Son-Rise program on the family as a whole. In response to the question, "do you feel that running the Son-Rise program currently has an impact on the rest of your family?", the author categorized the responses into benefits and drawbacks, and found that at the second and third time points, drawbacks ( $40 \%$ and $39 \%$ respectively) were reported more often than benefits ( $21 \%$ and $19 \%$ respectively), suggesting that the Son-Rise program had greater drawbacks for families than benefits. However, it should be noted that some parents who reported drawbacks also emphasized that the drawbacks were not severe or that their implementation of the program minimally disrupted their family life.

Trudgeon and Carr (2007) conducted semi-structured interviews to explore the impact on families of parents' implementation of a home-based EIBI program for children with autism. The interview focused on four themes related to the EIBI program: parents' experiences with the set up of the program, impact on family life, perceived benefits and disadvantages, and barriers and facilitators. The authors found that parents reported a mix of both positive and negative impacts from the program, but overall the authors concluded, "that the potential for stress on families may have been mitigated by benefits experienced through the EIBI program" (Trudgeon \& Carr, 2007, p. 294). These three studies offer insight into the evaluation of family impact of parentinclusive ASD interventions that should be used as a guide for future studies.

\section{Lived Experience of Families in ASD-Related Early Intervention Programs}

While quantitative designs are both appropriate and methodologically feasible in the examination of family outcomes in response to early intervention, Bailey et al., (1998) argue that, "the attainment of most family outcomes is a personal experience that can only be reported by family members themselves" (p. 315). In light of this, a phenomenological approach that 
explores the first-hand experiences of families participating in early intervention programs for children with ASD may be a more valid and valuable research design for assessing family impact. As Glynne-Owen (2010) argues, "with such an emphasis on an entirely quantitative approach, the voices of those that are being researched are not being heard" in ASD intervention research (p. 410). She further argues that a qualitative approach would be more inclusive of the individualized experiences and perspectives of children with ASD and their families. Therefore, through the exploration of the lived experience of families involved in parent-inclusive early interventions, a greater understanding of the impact of the intervention on the child, parents and the family as a system can be achieved. To date, the majority of phenomenological studies in the area of ASD focus on the lived experience of parenting a child with autism (Hoogsteen \& Woodgate, 2013; Woodgate, Ateah \& Secco, 2008; Benderix, Nordstrom, \& Sivberg, 2007), but do not focus on the experience of children, parents or families involved in parent-inclusive interventions.

\section{The Current Research Question}

In consideration of the significant impact of ASD on parents and families, the limitations of early intensive behavioural intervention, the emergence of increasing support for naturalistic behavioural interventions, evidence supporting the inclusion of parents in interventions for children with and without ASD, the limited evaluation of family outcomes in parent-inclusive ASD interventions, and the paucity of phenomenological studies of families' lived experiences in parent-inclusive ASD intervention programs, the current paper explores the first-hand lived experience of families in a parent-mediated intervention for toddlers with suspected or confirmed ASD (the Social ABCs currently ongoing at Holland Bloorview; Brian \& Bryson in prep.). The 
research question is: What is the lived experience of families involved in the Social ABCs parent-mediated intervention?

\section{Operational Definitions}

For the purpose of this paper, three terms are important to define. First, the term "parentinclusive" is used by this author to refer to interventions with a specific parent component as identified by the developer or reviewer of the intervention. Parent involvement may include training, education, mediating, delivering, implementing, and/or other direct involvement specifically related to the intervention. It should be noted that the author did not assume that "home-based" programs included a parent component, as it was often the case that the role of the parent in the intervention was ambiguous or unclear, and therefore these studies will be discussed separately from "parent-inclusive" interventions. Second, rather than defining "family" according to a priori theoretical or personal conceptualizations, the author chose to allow the participants to define family in their own way. Third, the abbreviation 'PRT' stands for Pivotal Response Training (Koegel, 1999a), which is described by its developers as a naturalistic behavioural intervention for children with ASD, meaning that the intervention is based on the principles of Applied Behaviour Analysis (ABA) and is implemented in natural settings using natural reinforcers (as defined above). PRT is the foundation of the Social ABCs intervention. It should be noted that in the interviews, respondents often used the term 'PRT' interchangeably with 'Social ABCs'.

\section{Scope and Bounds}

The primary purpose of this investigation was to explore the lived experience of families involved in a parent-mediated early intervention program for toddlers with ASD. The specific aim was to provide insight into the experience of families involved in the Social ABCs parent- 
mediated intervention, to identify the impact on the family as a system, with an emphasis on changes in family stress, family functioning and family accommodation. The rationale for this focus emerged from existing literature that highlights the significant positive impact of parent involvement in ASD interventions on child and parent outcomes, but with a limited focus evaluating family outcomes. This study used semi-structured interviews, following the completion of families' participation in the Social ABCs intervention phase, therefore precluding the option to examine quantitative pre-post changes in family outcomes related to the parentmediated intervention. Despite the bounds of the current investigation, this study offers a valuable opportunity to explore a novel and relevant area of research for families of children with ASD, while also contributing to the existing gaps in the literature by providing insight into the impact of the Social ABCs parent-mediated intervention on the entire family. 


\section{Chapter Three: Methods}

This qualitative study was guided by phenomenological inquiry with the goal of exploring the lived experience of families involved in the Social ABCs parent-mediated intervention study. Phenomenological inquiry is intended "to capture the essence or the underlying meaning of lived experiences as they are brought to light through the experiences of individuals" (Woodgate, Ateah, Secco, 2008, p. 1076). Given the aim of providing a rich description of the phenomenon of families' lived experience in the Social ABCs intervention, and how this lived experience impacted families, phenomenological inquiry was selected as the most appropriate approach to guide this work.

The Social ABCs is a parent-mediated intervention for toddlers with suspected or confirmed ASD. This intervention employs the evidence-based fundamentals of Applied Behaviour Analysis (ABA) in the form of Pivotal Response Treatment (PRT), with adaptations made for the toddler age group. PRT relies on children's motivation to develop speech and social skills in natural settings (e.g., in their home with parents) by incorporating child choice for objects of interest, variation in tasks and activities, reinforcement of all vocalization attempts, and use of reinforcers that are immediate and naturally tied to the child's interests and response. The intervention is taught to parents in their homes, which entails discussion of PRT principles and procedures, as well as in vivo coaching of parents' implementation of the PRT procedures as they play and interact with their child throughout daily routines. The purpose of the intervention is to target two areas of early impairment in ASD: positive emotion sharing and functional speech. Positive emotion sharing is defined as a smile, either in response to another person's smile, or initiated by the child, that is directed to the other person. Functional speech is defined as an utterance that is meaningful, intentional, and directed toward a communicative partner. The 
larger Social ABCs research study was conducted as a randomized controlled trial, and the Social ABCs experimental group received six months of intervention (i.e., three months of parent training followed by three months of parent implementation and follow up), while the control group received six months of waitlist, followed by six months of Social ABCs intervention, if parents were interested.

\section{Participants}

The larger Social ABCs study is ongoing in two sites - Toronto, ON and Halifax, NS. Participants in the larger Social ABCs study were randomly assigned to one of two treatment groups for a total of 6 months: 1) families of children in the Social ABCs parent-mediated intervention (experimental) group, or 2) families of children in the treatment "as usual" (control) group, who were offered the intervention at the completion of the 6 months. When the intervention started, children were between the ages of 19-33 months to capitalize on the critical period for early intervention that is associated with improved outcomes (Chawarska et al., 2008). Children were deemed eligible to participate based on clinically significant signs of ASD as defined by total scores on the Autism Observation Scale for Infants (AOSI, Bryson et al., 2008) of 9 or more, and/or total scores above the ASD cut-off on the Autism Diagnostic Observation Schedule (ADOS, Lord et al., 2000), and expert clinical judgment. Families were also required to meet several other eligibility criteria as follows: (1) for the duration of the 6 months of the Social $\mathrm{ABCs}$ intervention, families in the treatment group were required to abstain from receiving ABA/IBI interventions, participating in the Hanen workshops, having their child in full time child care for greater than $50 \%$ of the work week, and were asked to limit speech/language services and occupational/physical therapy to no more than 1 hour per week; (2) families must not have completed any previous training in the Social ABCs program; (3) families must live 
within a 50km radius of Holland Bloorview Kids Rehabilitation Hospital; (4) the parent being trained in the Social ABCs strategies required a strong understanding of English since the manual was written in English and the coaching took place in English. Children with significant sensory or motor challenges (e.g., those with visual impairment or significant Cerebral Palsy) were excluded from the larger study. Participants in the larger Social ABCs randomized controlled trial were recruited from two primary sources: from community clinicians and via the Infant Sibling study (see below for details). Community clinicians who were likely to come into contact with potential participants were provided with recruitment materials and information regarding the Social ABCs study. Community clinicians were asked to first contact the study coordinators to ensure basic inclusion and exclusion criteria were met before informing potential participants about the study. If the criteria were satisfied, the clinician informed the potential participants about the study, who were invited to contact the research coordinator if interested in participating. In the Infant Sibling study, siblings of children with an ASD diagnosis are assessed between the ages of 6-24 months to identify any clinical concerns or suspicions of early signs indicative of ASD. At each visit, if concerns are raised, parents are provided feedback by the senior clinician about the assessment findings, at which time, parents are informed by the senior clinician or research staff about the Social ABCs study and given a brochure with the contact information of the coordinator that they can contact if interested in participating.

All of the families in Toronto who had completed the Social ABCs parent-mediated intervention phase were invited to participate in this follow-up study $(\mathrm{n}=11)$. Consistent with the aim of phenomenological research, sampling from the larger study was used to recruit families who had experienced the Social ABCs intervention and were willing to reflect on their experience. Therefore, with limited families having completed their participation in the Social 
$\mathrm{ABCs}$ intervention phase, it was not feasible to ensure that diverse characteristics of participants were represented in the sample. It is important to note, however, that the richness of personal experience that can be derived from phenomenological research was prioritized in this study, recognizing that "the value of qualitative research lies in the particular description and themes developed in context of a specific site" (Creswell, 2009, p. 193). The inherent limitations with respect to generalizability and representativeness that characterize qualitative inquiry were acknowledged but did not preclude the selection of this methodology given its strengths in addressing the primary question of interest.

In total, seven parents from six families who had completed the Social ABCs intervention phase volunteered to participate in the interviews. The majority of the participants from each family were mothers trained in the intervention, with the exception of one father trained in the intervention, and one family where both parents participated in the interview. The participants ranged from 36 to 44 years old, with a mean age of 40 years old. Of the participants' education levels, two had completed college and five had completed university. Three of the mothers selfidentified as Caucasian, one as Asian, one as Jewish, one as Italian, and the one father selfidentified as Colombian. All parents were married, and four families had at least one older child in addition to their child with ASD. All of the participants' children had a confirmed diagnosis of ASD prior to starting the Social ABCs intervention phase. Of the children with ASD, three were boys, and all were between the ages of 2 years, 10 months and 4 years, 8 months at the time of the interview. It should be noted that for the majority of families (5/6), there was an average time lag of 9 months (range: 3-19 months) from their completion of the Social ABCs intervention to their participation in the interview, with the exception of one family who had completed the intervention phase 27 months prior to the interview. This lag in time raises the possibility that 
other factors (e.g., developmental changes, new family stressors, etc. that occurred following the completion of the intervention program) may have contributed to parents' reflections about the experience. In addition, it raises the possibility that other interim factors may have influenced their responses (e.g., developing an increasingly positive perspective after increased gains postintervention).

\section{Procedure}

The Research Ethics Board at Holland Bloorview Kids Rehabilitation Hospital (Bloorview Research Institute) approved the primary study "Social ABCs for Toddlers with Suspected Autism: Evaluation of a Parent-Mediated Intervention”. The current study was approved at Holland Bloorview Kids Rehabilitation Hospital and Ryerson University as a new study for the purpose of interviewing families regarding their experience in the Social ABCs intervention phase of the primary research study.

Recruitment Method. As noted above, the families of the larger Social ABCs study were recruited from two primary sources: community clinicians and the Infant Sibling Study. All of the families in Toronto who had completed the Social ABCs parent-mediated intervention phase of the larger research study were invited to participate. It should be noted that while some families ( $n=3$ ) had initially been randomized into the experimental Social ABCs group, others $(n=3)$ were initially randomized into the control group, and received the Social ABCs intervention six months later. Irrespective of their initial randomization in the larger Social ABCs study, any family that had completed their participation in the Social ABCs intervention phase of the larger study was invited to participate in this follow up study, as the goal was to maximize the sample size and generate rich descriptive data to gain insight into the families' lived experience in the Social ABCs intervention. 
The families were emailed or mailed (depending on the available contact information) an information letter inviting them to participate in this research opportunity. The letter was sent by one of the trainers from the original phase of the larger Social ABCs research study, who was known to the families. If families had not responded within 7 days of sending the recruitment letter, a phone call (following a script) was made by the research staff known to the families to inform them of the opportunity. Six families indicated interest in participating, two families declined, and three families did not respond. To encourage interest from families to participate, and to express our appreciation for the contribution of potential participants (Donalek, 2009), the author included on the information letter that a twenty-dollar gift card to Indigo bookstores would be provided for families' participation in the interviews.

Interviews. To gain a deep and descriptive understanding of families' lived experience of the Social ABCs intervention within a phenomenological framework, a qualitative research design was deemed most appropriate for this study (Trainor \& Graue, 2013). Semi-structured face-to-face interviews were conducted using open-ended questions, some of which were guided by the literature to address topics relevant to family outcomes of early intervention for children with disabilities. This structure allowed the author to frame the discussion in advance, while enabling participants to speak in their own words rather than those of the author (Qu \& Dumay, 2011). This structure also allowed for the author to build rapport with the participants, to ask planned and unplanned probes in response to participants' comments, and to increase the participants' comfort level with the author, which ultimately allowed for the greatest detail in responses (Richards \& Morse, 2013).

In light of the paucity of research evaluating the potential impact of parent-inclusive interventions on family outcomes (Karst \& Van Hecke, 2012), the lived experience of the Social 
ABCs parent-mediated intervention was explored through semi-structured interviews to gain a family perspective with the aim of better understanding the impact of the Social ABCs on the family as a system. As highlighted by Greenstein (2001), an "emphasis on holistic understanding makes qualitative methods especially well suited to studying families" given their capacity to gain multiple perspectives (p. 98). While the definition of family is well acknowledged in the literature as a fundamental challenge in family research, defining family is unavoidably fundamental to studying families (Greenstein, 2001). Therefore, rather than defining "family" according to theoretical or personal conceptualizations, the author chose to allow the participants to define family in their own way.

With the goal of capturing the meaning of the lived experience for families involved in the Social ABCs intervention, a collective family interview would have been ideal to fully reflect the family's collective experience (Donalek, 2009). However, given the very young age of the toddlers and siblings during the families' participation in the Social ABCs intervention phase, children were not invited to participate in the interviews, because it would be difficult to obtain meaningful responses from them, especially given their very young age at the time of the families' participation in the intervention study. Instead, an interview with both parents was offered to families interested in participating, as it is acknowledged that the views of one family member do not necessarily represent those of the family as a whole (Greenstein, 2001). The author recognizes that reliance on the views of only two family members also has its limitations with respect to representing the family as a whole, but the author attempted to obtain at least more than a single perspective within the family. Moreover, having more than one family member present in an interview, interaction is stimulated, disclosure is encouraged, and insights are enriched (Donalek, 2009). Regrettably, it proved especially difficult for both parents to 
participate in the interview (due to limited availability), and therefore the lived experience of families involved in the Social ABCs was primarily elicited from the perspective of the parent trained in the intervention, with the exception of one family where both parents contributed to the interview. However, while it was not possible to interview multiple family members to obtain a broader, more collective or holistic perspective of the experience, one individual informant is nonetheless a valuable source to provide insight into families' collective experience in the Social ABCs intervention (Donalek, 2009). The number of participants from each family (one or both parents) was determined based on the interest and availability of individual family members.

Several steps were taken to maximize the trustworthiness of the data. The interviews were audio-recorded, transcribed and then listened to a second time. In addition, written notes were recorded during the interview to follow-up with unplanned probes as needed and to record any relevant non-verbal communication from the interviewee, increasing the trustworthiness of the data. The interview was conducted at a time and in a location that was most convenient and comfortable for the participants.

The semi-structured interviews were conducted using open-ended questions. According to phenomenological inquiry, a minimal number of broad open-ended questions are asked to elicit the participant's story and interpretation about an experience (Trainor \& Graue, 2013; See Appendix D). To allow participants the opportunity to speak in their own words, to spontaneously describe what really mattered to them about the experience, and to build rapport with the interviewer (Qu \& Dumay, 2011), the author first asked an introductory question (question 1). This question elicited responses deemed significant to better understand the lived experience of families' participation in the Social ABCs. Furthermore, by requesting the interviewee to spontaneously talk about their child and the intervention, it allowed the author to 
gain insight into their perceptions of their child and their use of language ("disability", "special needs"), in turn, dictating the author's use of language to be consistent, appropriate and respectful of each family. At the conclusion of the interview, an unplanned summary question (question 6) was asked to capture anything that may have been missed during the interview and to once again allow parents to speak freely and emphasize issues of importance that may provide further insight into the Social ABCs lived experience.

For the purpose of exploring the impact of the Social ABCs parent-mediated intervention on the family as a system, the author asked four open-ended direct questions that were guided by research on family outcomes of early intervention for children with disabilities (Bailey et al., 1998; Bailey et al., 2006; Epley, Summers, \& Turnbull, 2011; Turnbull, Summers, Lee, Kyzar, 2007; Raspa et al., 2010). These direct questions were intended to elicit direct responses on a specific topic (Qu \& Dumay, 2011). Therefore, the literature provided a framework for assessing family outcomes relevant to early intervention programs for children with disabilities that guided the development of the four direct interview questions.

The framework proposed by Bailey et al., (1998) was influential in outlining the direct interview questions. In order to better understand families' perceptions of the Social ABCs experience, question 2 ("Did the Social ABCs experience make a difference in your child's life? If so, how?") was intended to explore the families' perception of the intervention received from the Social ABCs, and whether it was perceived as beneficial or not for their child's developmental outcomes. Probe 1 was used following this question if parents had not previously discussed their child's development or learning (in the context of the Social ABCs). Question 3 extended families' perception to explore the impact on the family, beyond perceptions of the impact on the child. Probes to address this question emerged from the literature on family quality 
of life, which, according to Bailey et al., (2006) is recognized as "an ultimate goal" of early intervention (p. 243), and is an appropriate index for evaluating family outcomes of early intervention (Epley et al., 2011). The family quality of life literature was reviewed with the purpose of identifying probes to elicit direct responses to address this exploration (Summers et al., 2005; Zuna, Turnbull \& Summers, 2009). Family quality of life is conceptualized as encompassing the three primary impacts of a child's disability on the family: stress; family functioning; and accommodations to daily routines (Summers et al., 2005). The Beach Center Family Quality of Life scale (Summers et al., 2005; Wang et al., 2006) and the Family Quality of Life survey (Brown, MacAdam-Crisp, Wange, \& Iarocci, 2006), as well as quantitative measures of stress, family functioning and accommodations were reviewed to guide the construction of the probes (Family Stress and Coping Interview for Families of Individuals with a Developmental Disability (Nachshen, Woodford, \& Minnes, 2003); Family Adaptability and Cohesion Evaluation Scales - III (Olson, Sprenkle, \& Russell, 1979); Family Environment Scale (Moos, 1974); Ecocultural Family Interview (Weisner, 2002); and The Routines-Based Interview (McWilliam, Casey, \& Sims, 2009)). These probes were used if parents had not previously addressed the topic in response to the broader question (3). Questions 4 and 5 are based on the theoretical assumption that at the conclusion of an early intervention experience, families should feel that their goals have been met and that they are optimistic and more hopeful about their child's future (Bailey et al., 1998). For a list of the interview questions, please see Appendix D: "Exploring the Lived Experience of the Social ABCs Parent-Mediated Intervention Study SemiStructured Interview Questions”. 
One dyad interview (both parents present) and five individual interviews were conducted for a total of six interviews. The individual interviews all included trained mothers, and the dyad interview included one trained father and his wife. The interviews ranged from 30 to 90 minutes.

Setting. All of the interviews took place within a $50 \mathrm{~km}$ radius of Holland Bloorview Kids Rehabilitation Hospital in Toronto. The majority of the interviews were conducted in the family's home, with the exception of two; one at a community centre and one at a parent's office.

\section{Data Collection}

In consideration of ethical issues in data collection, the purpose of the research was fully disclosed to participants who were then asked to sign an informed consent form prior to their participation in the study. If more than one family member participated, the researcher ensured that each participant gave his or her individual consent. Confidentiality and anonymity was maintained with the use of pseudonyms for all family members and research staff in written transcripts. All study-related records were kept confidential and identifiable only by a family identification number to protect the anonymity and confidentiality of the participants. The records were stored on password and encrypted data keys for transportation and then on password protected computers. Hard copy documents are currently stored in a secured and locked cabinet at Holland Bloorview, and will be discarded after 7 years. It was possible that families may have felt uncomfortable answering some of the questions or elaborating on some of the concepts established during the interview, and therefore, families were reminded that they were free to refuse to answer any questions and/or stop the interview for any reason at any time. Additionally, families were informed that they have the right to withdraw from the study altogether, and the audio-recordings that had been made before their withdrawal would be 
destroyed. However, it was highlighted to families that their audio recordings and data could only be removed up to July 1, 2013, after which withdrawal from participation was not possible as the study was complete. There were no further known harms, or potential risks, from participating.

\section{Data Analysis}

Guided by a phenomenological approach, thematic analysis was used to interpret and understand this qualitative description of the lived experience of families involved in the Social ABCs intervention. Therefore, each transcript was read in its entirety multiple times to identify significant statements in order to find meaning and understanding through themes. According to Donalek (2001), the goal of qualitative family research is "the creation of a description of the family phenomenon in question that is grounded in themes common to the experience of families generally while, at the same time, reflecting the experience of individual families" (p. 26). Within the research approach of phenomenology, the goals of the current study were to gain insight into the essence of the families' lived experience in the Social ABCs intervention, to provide a rich understanding of the meaning of this experience for families, and to uncover phenomena related to the impact of the Social ABCs parent-mediated intervention on the family. Therefore, this analysis focused on participants' interpretations of the Social ABCs experience for the child and the family as a unit, and more broadly, the similarities and differences in participants' interpretations of the lived experience for families involved in the Social ABCs intervention. The resulting information from the interviews should enrich the reader's understanding of the lived experience of the Social ABCs, and provide insight into the family impact of the Social ABCs parent-mediated intervention. 
Within phenomenology, strategies for data analysis are difficult to find and often not explicitly discussed (Flood, 2010). Instead, phenomenological analysis, or interpretive analysis, involves reading, reflection, writing and rewriting that is an on-going and iterative process that "enables the researcher to transform the lived experience into a textual expression of its essence" (Richards \& Morse, 2013, p. 198). Consistent with the analytic goal of engaging with the data from an unbiased perspective, the author reflected on her personal experiences, beliefs and preexisting thoughts on this topic in order to put them aside and interpret the data with an open mind (i.e., "bracketing"; Richards \& Morse, 2013). However, some authors (Flood, 2010) have argued that it is impossible for an author to ever be completely rid of his or her background knowledge when researching a topic worthy of interest, and that the author's personal knowledge can be useful to phenomenological inquiry.

The research question was framed by the literature that then influenced the design and focus of the interview questions to elicit information regarding family impact related to the Social ABCs lived experience. For the purpose of this analysis, the transcripts were organized and coded according to interview question to help identify common meanings and patterns across participants. Given that the first and final questions were non-directed, they were interpreted using emergent thematic analysis. Because the directed interview questions (2-5) guided some of the topics addressed, the four directed questions and their accompanying planned probes, were not appropriate for an emergent thematic analysis; they thus required an alternative analytical strategy. For these questions, thematic analysis was used according to each topic (e.g. effect on child's life, effect on family's life, family goals, family's view of the future for their child). Each interview question was analysed separately at first, with the aim of highlighting patterns specific to each topic but across participants. Themes were then identified across all 
questions to identify major patterns and meanings that provide insight into the essence of families' Social ABCs lived experience.

Phenomenological analysis is a process of "developing a description of the phenomenon that leads to an understanding of the meaning of the experience" (Flood, 2010, p. 10). Braun and Clarke's (2006) phases of thematic analysis were followed to identify, analyze and describe themes within and across the data.

In the first phase, the author familiarized herself with the data by transcribing the interviews verbatim, listening to the interviews a second time to ensure transcription accuracy, and reading the interviews in full twice to identify initial ideas, patterns and meanings that were used for coding in subsequent phases. In the second phase, the author generated initial codes to highlight features of the data that appeared interesting and meaningful to the phenomenon under investigation, the lived experience of families in the Social ABCs. To develop codes, the researcher reviewed the transcripts manually, highlighted segments of the data, and made notes in the margins of the transcripts to indicate possible patterns or interesting aspects of the data set. A codebook was created to record the names of the codes, a definition of the code, and specific examples to identify the code from participants' responses (Richards \& Morse, 2013). Participants' responses to non-directed interview questions 1 and 6 were coded by organizing segments of the text into categories that were then labelled by an "in vivo" term, a term based in the actual language of the participant (Creswell, 2009). Participants' responses to directed questions 2-5 were coded individually for ideas or meanings within individual interviews, thus identifying meaning within the participants' responses, and then the data were organized into categories of common patterns and meanings across families. At a broader level, the third phase involved searching for themes from the codes identified within and across families. A theme 
"runs right through data and is not necessarily confined to specific segments of text", and is therefore more pervasive than a topic or category (Richards \& Morse, 2013, p.160). The author sorted the codes into potential themes and collated the relevant coded data into the outlined themes.

In the fourth phase, the themes were reviewed and refined to determine if the collated extracts from the data formed a coherent pattern for each theme, and to determine the validity of the individual themes in relation to the overall data set. During this phase, the author consulted with her supervisor to review the themes and to reflect on the evolution of the author's ideas about the story the data were telling (Starks \& Brown Trinidad, 2007). By the end of the fourth phase, the author had a clear understanding of the different themes and how they fit together to describe the lived experience. The fifth phase involved naming and defining the themes. In the sixth and final phase, the author prepared the final analysis and write up of the findings based on five identified themes, providing rich and descriptive evidence from the data to support the themes presented and to accurately describe the overall story. The end result of this analysis was the development of a representation of the lived experience for families involved in the Social $\mathrm{ABCs}$ parent-mediated intervention. In addition, data from the demographic form (collected as part of the larger Social ABCs research study) were summarized and described using descriptive methods.

Reflection of the methods and evidence on which the findings are based is valuable for evaluating the trustworthiness, or accuracy, of the findings (Check \& Schutt, 2012). While some of the findings were based on parents' perspectives that were elicited in response to the author's direct questions, there was a significant overlap with parents' spontaneous statements that emerged from undirected questions, indicating that the findings, for the most part, reflect what 
the parent would have said had the author not guided the questions. In addition, the author included rich descriptions from multiple parents' perspectives to convey each theme identified, and discussed parents' perspectives that were contrary to dominant themes, thus representing the full range of families' lived experience. To increase the author's confidence in the findings, and to identify novel contributions to this research area, the themes were considered in light of existing research on parent-inclusive interventions for young children with ASD and their families. And finally, the author acknowledged (below) her background and her biases that may have influenced the interpretation of the findings.

\section{Author's Characteristics}

The author's background in psychology (albeit predominantly in quantitative analysis in research and clinical practice), her experience working with children and families in both EIBI and parent-mediated models of early intervention, and her belief that parents can play a valuable role in early intervention, undoubtedly influenced the design, analysis and interpretation of the present findings. It is therefore important to reflect on and identify my biases and personal experiences that may have potentially impacted my findings, a process referred to as 'reflexivity' (Trainor \& Graue, 2013). First, while working in EIBI settings, I was dissatisfied with the limited parent inclusion in the intervention process for families of children with ASD, as it was evident there was a disconnect between the child's experience at home and the EIBI setting (in terms of the child's skills, expectations and behaviour management). Second, my frustration with the current early intervention system for children with ASD, and my own feelings of helplessness from wanting to help families struggling to meet the needs of their child, further motivated my interest in parent-inclusive interventions. And third, my first hand experience of families who have been positively impacted by their involvement in parent-mediated 
interventions, confirmed my passion to explore this area. My principal bias, based on prior knowledge and experience, was a hypothesis that families' participation in the Social ABCs would be generally positive. I expected that children would show some improvement in social communication skills, and that parents would, for the most part, report feelings of competence and empowerment from learning the tools to help their child with ASD. I also acknowledge that I expected that some parents might report feelings of stress or pressure from taking on a role perceived as being responsible for their child's response to the intervention. I was however, generally unsure about how the Social ABCs would impact the family as a whole, as it is possible that participation in a parent-mediated intervention could disrupt family life and ultimately result in overwhelming stress on the family. Acknowledging these biases is especially important for the validity of the findings and for creating an open and honest narrative with the reader (Richards \& Morse, 2009). 


\section{Chapter Four: Findings}

Participants provided insight into the lived experience of families involved in the Social ABCs parent-mediated intervention for toddlers with ASD. This section describes the five main themes and corresponding subthemes that were identified within and across interviews.

\section{Theme 1: Impact on Child}

One of the dominant themes that emerged from parents' responses was the impact the Social ABCs had on their child. This theme was defined as improvements in the child's development, specifically in the areas of communication and engagement.

Communication. All seven parents expressed having observed improvements in their child's communication development that they attributed to their participation in the Social ABCs intervention. Parents highlighted improvements in their child's expressive and receptive language, vocabulary, joint attention, vocalizations, and speech.

Anne: Her talking and her speaking, is leaps and bounds, she's talking all the time now... she understands more than she did before we started the Social ABCs... it's made a huge difference in her life because she's able to communicate more now with us... it changed her life immensely because of...just communicating and being able to get through her day and know she's gonna get what she wants.

Tom: ... we gained a lot of vocabulary... joint attention, very nice eye contact... [During the Social $\mathrm{ABCs}$ ] was the first time she started requesting things, so it was very valuable. Judy: ... the one thing we gained from her was her vocalization from it [Social ABCs]. I think she realized ... that she does need to vocalize to get a point across.

Leah: ... right now to this date he's actually where he is [supposed to be] for speech and language... he made huge gains that I personally would attribute to the PRT.

Ruby: I think it has helped with social communication... just communicating with adults and his little peers...I see it as it's made a difference.

Ellen: ...he started to communicate verbally... he start talking ... but before that, before the study he didn't even say any words, like his vocabulary was very limited. 
When participants were asked directly about their family goals, the subtheme of child communication also emerged, with the majority of parents (4/7) reporting that improved child communication was one of their family goals before beginning the Social ABCs intervention. The emphasis was on seeing improvements in their child's expressive language skills, for which two of the four parents reported that they felt this goal was met. According to the parents who felt that this goal was not met, they did highlight the significance of the intervention in helping get closer to achieving this goal.

Tom: ... we wanted to see Ava doing more things... communicating more... ya, ya [the Social ABCs helped achieve this goal]... Ava gained a lot of vocabulary...

Judy: Ya, that she would speak (laughs)... I was hoping she'd be making sounds that would eventually develop into words.. it didn't happen.. I still was content that there was still some progress in there.. so.. our goals were met, but... they were adjusted a bit...

Engagement. In addition to communication gains, some parents highlighted improvements in their child's level of engagement as a result of participating in the Social ABCs intervention.

Mary: ... a lot of people tell us that her social side is much stronger now and that she is more aware of her surroundings, more interactive with people and the environment...

Judy: I thought there was a little bit more engaging...

\section{Theme 2: Impact on Parents}

Several parents commented on the impact the Social ABCs intervention had on them personally, across a variety of domains. This theme was defined as improvements in parents' skill acquisition and knowledge, and in parents' view of the future for their child. This is an important and relevant theme to highlight in the context of a parent-mediated intervention. 
Skill acquisition and knowledge. Some parents (4/7) reported that their participation in the Social ABCs improved their skills and knowledge related to interacting with their child. Specifically, parents commented on learning how to communicate and play with their child, as well as how to help their child learn.

Ellen: ... we learned a lot how to communicate with Ben, how to play with Ben... we learned the importance of playing with a child.... so when you play with him, if he have fun and he's excited, then he started talking with us, but if you're boring then he's quiet (giggling), so through playing he's communicating with us.

Tom: ... through these exercises and this study, we had the opportunity to learn more what to do in certain situations and try to help her learn more things... we had the chance to interact with Ava more and more closely which we weren't doing before the ABCs... Mary: I just didn't know how to make connections with her, and I think that [the Social ABCs] really helped with that as well for all of us... Tom: in that sense it changed us and before that we didn't know what to do...

When participants were asked directly about their family goals, the theme of parental skill acquisition also emerged. Some parents (3/7) identified wanting to learn how to help their child, and felt that this goal was met through the intervention.

Ellen: The goals that we hope from the study, like... we learn actually, being a parent, I achieve my goal [to] learn the skills to help Ben.

Leah: Really just... trying to learn the different techniques to help him... Oh ya definitely, I think it exceeded our family goals because... the gains that he made are unbelievable.

Increased hopefulness. All six families (6/7 parents) shared the view that the Social ABCs had increased their hope for their child's future. Whether it was by realizing their child's current abilities or their child's future potential, all six families were more optimistic in their view of their child's future.

Anne: I think Lucy is going to do well, I realize that now, and now that she has the words to express herself and express what she wants to say, she is going to be fine... in terms of her future I'm not as concerned as I was before.

Tom: Well, from my point of view, I think that it kind of give me the whole concept that 
Ava was able to learn... I think through the ABCs it changed our point of view of her capabilities of doing things because we saw her doing new things and learning things and I think it was a very good positive way of seeing Ava and what she was able to do in life.

Ruby: I feel very excited for Josh, I think he has made huge gains, again I'm hoping the PRT is a part of that and I do believe it is socially, so I feel very bright about his future... I think socially he is going to do well, and I do believe the PRT is helping with that.

Judy: My view of the future... I think with the Social ABCs that actually helped us have some kind of hopes and goals.

\section{Theme 3: Impact on the Family System}

A third theme that emerged was the impact of the Social ABCs on the family as a system. This theme was defined as improvements within the family system, with an emphasis on three subthemes: family stress, family relationships, and family accommodations to daily routines.

Family stress. Within the subtheme of family stress, the majority of parents $(6 / 7)$ expressed that they experienced a decrease in stress related to their participation in the Social $\mathrm{ABCs}$ intervention. Although the specific reasons provided to explain the decreases in family stress varied across parents, there is uniformity across responses highlighting the significance of the Social $\mathrm{ABCs}$ intervention as having improved family stress.

Anne: ... our stress has decreased a lot, number one: we understand what she wants, number two: she can communicate, number three: basically it's more... harmony within the house, and her behaviour has decreased.... things got a lot easier for us, I find, it was obviously less of the screaming from Lucy, and more I guess harmony within the family and not being stressed out.

Mary... it probably decreased our stress because we got to feel a little more in control of what we were doing for her right... it's less stressful than the IBI ... because with the way that IBI usually goes there is a lot of tantrums, a lot of fighting, a lot of stuff to overcome, whereas with the PRT everybody is happy (laughing).

Ruby: ... having another [intervention] option helped relieve some stress and I said ok this is a different avenue to take.

Leah: ... because he [Will] was learning to communicate, his frustration levels went down...when you see your child frustrated it's obviously frustrating for the whole family, 
and then it obviously allowed for Will to get a long better with his brother... and for us to communicate obviously.

Some parents (3/7) highlighted the event of receiving a diagnosis as relevant to changes in family stress. Parents emphasized that stress increased for the family when their child was diagnosed with Autism Spectrum Disorder, which occurred right before participation in the Social ABCs intervention for these families.

Mary: The changes were all at the diagnosis I'd say (laughs), that was just constant stress throughout.

Ellen: Before we found out his diagnosis, we read a lot of information about autism so...the stress level was much higher so we don't know what's going to happen to him, maybe he's not talking, he's not communicating with people, and what will happen to him, maybe he have to go to a special school... at that time our stress level was very high.

One mother explained that her experience of participating in the Social ABCs intervention was initially "stressful" because it was a new intervention with hopeful but uncertain outcomes. This mother commented that although her initial stress was related to starting the Social ABCs intervention, she emphasized that her child's progress in the Social ABCs intervention decreased her stress.

Leah: I mean it was stressful just because you're going through like a new therapy, you didn't know what the outcome was going to be, you didn't know if it was going to work, ... but definitely by the end of it and when you can see his progress... like it was less stressful because you knew that your techniques actually were making a difference.

Family relationships. While the majority of parents reported improvements in the dynamics and relationships within their family that they attributed to their participation in the Social ABCs intervention, a few parents reported insignificant or no change.

Trained parent and child with ASD. Four of the seven trained parents expressed that their relationship with their child had improved throughout the intervention.

Tom: At the beginning it was a little more difficult because she didn't want us around when she was playing, and when we tried to interact with her she wasn't very happy with 
it, she just wanted to do her own thing... but through the training we learned we needed to be persistent... I guess little by little we get closer to Ava and she learned that's the way it would be from that point on.

Ellen: ...the more playing with him, if we are communicating more, then our relationship is closer... I understand Ben more about him and I think that the relationship will be closer... from the Social ABCs they teach us how to communicate with the child... then for sure the relationship will be closer.

In contrast, one trained mother reported that her relationship with her son did not change as a result of participating in the Social $\mathrm{ABCs}$ intervention. As she highlighted, the intervention is intended to be "natural" and "second nature", and thus would not be expected to impact her relationship with her son.

Ruby: ...our relationship has stayed the same, because if you do it, in my belief is if you do it right, it is second nature, it is not like he knows he is sitting with me and doing work, it is natural... so I can't say it has really impacted him in a negative way and I don't see how it has changed the relationship in any way.

A unique perspective from one mother highlights the significance and relevance of the trained parent as a motivator and natural reinforcer for the child's language development. As this mother emphasizes, she saw her role as trainer powerfully contribute to her son's communication gains throughout the intervention.

Leah: Like obviously I'm probably a motivator as well, you know next to Thomas the Train, so the dynamics worked extremely well, cause I think ...if there was someone else...coming in and I was just sitting on the side lines, I don't know, and it's nothing to do with Sabrina [research trainer], but as a parent I think they're more motivated by you interacting with them and...I don't know if the success rate would be as high as if your own mother or father were doing it.

Non-trained parent and child with ASD. While one parent reported improvements in the non-trained parent's understanding of their child, most parents indicated improvements in their child's level of interest, communication and closeness with the untrained parent.

Anne: ... my husband...understands her more, like before he didn't even understand her, and now you know, it makes it for a better, I guess you could say a better way of just 
enjoying somebody and understanding what somebody wants.

Tom: I think it improves a little because you [Mary] were mentioning before she [Ava] didn't want to be around you and then we started coming out with these activities that require tickles and flying and jump and actually I remember her looking for you sometimes, requesting tickles or playing...

Ellen: Oh, it's great, it's great! The relationship is much closer, like Ben is always asking if his daddy will come home, or if he's not coming home, he seems not happy... he also enjoy the time when his daddy come home and is playing with him.

Two trained mothers reported that the relationship between their spouse and their target child was not impacted by the Social ABCs intervention.

Ruby: No, there were no changes [between Josh and his father]

Judy: I find that I'm her number one reliant. Her father and her 'cause of the study, he did it a little bit, but he really wasn't that consistent all the time... So I'd say it hasn't really changed, like that didn't change.

Parents' relationship. While the majority of parents (6/7) reported improvements in their relationship with their spouse, one parent reported no changes related to their participation in the Social ABCs. Improvements included comments about less arguing, more quality time spent together, decreased stress, improved hopefulness, and teamwork. A few parents also highlighted the challenges of training their spouse and the benefit of receiving neutral training from outside the marriage (as was the case in the Social ABCs).

Anne: ... it's gotten a lot better because like it's not as stressful as it was before, we're not arguing as much as we were before... you know it's not me arguing with my husband about "well she's trying to say this, can't you see that"... our relationship, our marriage has gotten better, we go out more than we used to, and again because no one understood her so no one could take care of her... we're able to sit down and make those decisions... talk about things, and catch up...

Tom: I remember Mary making me realize some things that I ...didn't remember and that was very useful so I think that we worked like a team and we did very well, it was a good interaction... Mary: Well I think that's the big thing that when training comes from the outside it relieves some of the stress of people not wanting to hear it from their spouse so it is very neutral advice in that way...I don't know, some couples maybe are better with that but I think a lot of couples really don't appreciate being corrected by their spouse... 
Ellen: because we have the study together and then we can help Ben together, so the more time we spent together, then it bring our relationship closer as a family...so it also helped me to bring down the stress level and so right now like our relationship is better, I think it's better, than before, once we found out the diagnosis.

Leah: No.. not really, it was challenging training your spouse, right, because you're pretty critical so I mean that part was a little bit challenging and difficult, but I mean no we have a very open relationship in terms of Will's therapy and to do everything possible to help him, we're both on the same page so there was no issues whatsoever.

Child-sibling relationship. Of the four families who had an older child in addition to their child with ASD, three of the four parents commented on the improvements between the child and his/her sibling in relation to the Social ABCs experience, while one parent indicated there were no significant changes. According to parent report, improvements in the child-sibling relationship were felt to be related to improved communication and social interactions for the child with ASD that resulted from their participation in the Social ABCs. Interestingly, two parents reported that they taught the sibling about the Social ABCs intervention in order to include the sibling in the intervention process. This is especially important as it highlights the extent of family involvement, the feasibility of the intervention, and the potential impact of the Social ABCs intervention on the family as a system.

Anne: And her relationship with Lucy is wonderful because, again, they can communicate more and Aly [older sister] is not saying "huh, what, mommy?"

Ruby: Well Josh seeks him out, I think it has helped socially with Josh, as I said he seeks out his older brother, and definitely is engaged so it's positive from Josh's perspective...

Leah: ... I mean it got a little bit better... they always got along, again but just because of where Will's communication level is now, they're the best of friends...

Judy: No, no.. You know, she's still not that close, she's still like a typical kid when it comes to a kid on the spectrum in the sense that where she doesn't socialize so much with her brothers, but when she does, like you know, she has an ok relationship, it is a love hate thing, from the study's perspective it had no impact. 
In addition, a few parents mentioned the initial challenge for siblings when the child with ASD received specialized attention from the Social $\mathrm{ABCs}$ trainers in the home.

Ruby: Any time the attention is given to Josh and not Aaron, he's [Aaron] like what's going on, why does he have this, what's she [Social ABCs trainer] doing, but it was fine, and I explained to Aaron why we were doing it, and said it was Josh's homework, and he [Aaron] was ok.

Parent-sibling relationship. Although none of the parents reported an observable impact on their relationship with other children in the family from having participated in the Social ABCs intervention, two mothers reported that they spent more time with their other child because of their involvement in the study.

Anne: ...we spent more time with her [Aly, older sister].

Leah: James [older sibling] was out of the house most of the time, and with me being at home I spent more time with both of them so it worked out well for me. But I wouldn't say there were any changes.

Parent as interventionist. Although not originally included in the protocol, the author asked an unplanned probe about the parents' perception of their experience as parent and trainer. This probe elicited a range of comments described as "natural", "challenging" or "empowering".

Natural. The majority of parents (4/7) reported that their experience as both parent and trainer in the Social ABCs intervention was "normal", "natural" and easily incorporated into their everyday lives. This theme is especially relevant to the feasibility of implementing the Social ABCs intervention that has been identified as a theme in subsequent questions.

Anne: I do have my ECE, I've had it for many years, and at one point in my life it was all I breathed and knew about was children, so when I started having kids this is all I know, this is all I do, I just play with kids all the time, so in that aspect for me to go from mom to trainer I kind of incorporated the two together... so when I became a trainer for her it was almost as if I wasn't, like it was just very natural... so I mean like it wasn't much of a change for me, it was very very natural.. like I said, ok I can incorporate that into what I'm doing already. 
Tom: Actually I kind of enjoy it... but I don't think there was any particular situation that I feel that is difficult to interact as the trainer and the father at the same time. It was very kind of normal.

Ruby: I found it really helpful to me to have something that I felt good that I could do... and that I could continually use in a natural way with Josh.

Judy: Mmmm I just incorporated it, I just find that I was trying, because I've been with Quinn again, whether it be the social ABCs or anything, I've always been mom, however I'm always the one that has to follow through with whatever is being taught so I also have to be the tough one so when it came to the social ABCs it was just let me just continue being the tough one for her.. so no I didn't find it difficult you know.

Challenging. Four parents expressed the challenges experienced of taking on the role of

both trainer and parent throughout the Social ABCs intervention.

Tom: As a trainer and dad, I would say when we reached the point when we were kind of running out of activities for Ava... we reached the point where I was struggling to come up with new ideas and at that point it becomes a little tricky where to go from there... ya, at the completion ya at the end.. we were doing everything that we learned but still I was switching toys we were bringing new toys, taking away some, but she had no interest in doing this and she was trying to go around and there was nothing I could engage her in and at that point, that was a little challenging.

Ruby: Taking on both roles... I mean it was, I felt somewhat pressured because I thought ok I've got to be doing this more often, it's hard, it's something that in the beginning I was just like I have to pick a time in the day to do it, where it would be nice if other people were consistently doing it with me... I felt somewhat pressured because I thought I've got to do this and this is falling all on me, and that was tough at times.

Ellen: So being a mom it's sometimes difficult if you want to teach him something... it is difficult to change being a mom that give him everything without him asking for things, so that means I think that it is difficult to change what I normally do to a routine that unless he ask for it and then I give him things.

Leah: I mean it's obviously easier just paying someone to come in and do your therapy.. but I think just seeing his progress even after the first few weeks, I could see I was making a huge difference. I mean it was tough at the beginning because sometimes you just, like you just felt frustrated, you couldn't find something to prompt him with, he wasn't responding, he was you know acting out, he was getting frustrated which makes you frustrated... but you just kind of have to move on, and go forth, but again the progression that I saw, you could see a huge difference. 
Empowering. One mother, who initially commented on the challenges of adopting the dual role of mother and trainer, highlighted how empowering it was for her to use the Social ABCs with her son. Although many families did not explicitly report the role as "empowering", this notion is felt to be extremely important, as it can be understood as a central goal of parenttraining models.

Ruby: I mean I like it because it is empowering for me and it gives me a tool for Josh... I found it really helpful to me to have something that I felt good that I could do.

Family accommodations to daily routines. Parents' comments about the feasibility of implementing the Social ABCs intervention within the context of daily routines were common, but somewhat variable across parents.

No accommodations required. Two parents expressed that the Social ABCs was feasible and easily incorporated into their routines, and therefore it did not require accommodation to their daily routines as a family.

Anne: No, it didn't affect us at all. Because it was just a very very natural way of doing it throughout the day.. I didn't feel like I was stressed out about it, I didn't feel like it was hard work... we just did it all the time, it wasn't that we stayed home to do it, whatever we had to do, we just did it and we incorporated it into whatever we were doing.

Leah: The Social ABCs were very accommodating to my schedule... like I said, it's not like you sit there and say ok we're going to block off this hour for PRT training, you do it throughout the day, it's a very natural way of therapy, no it didn't upset my routine whatsoever.

Initial accommodations required. Two parents expressed that initial changes were required in their daily routines to accommodate the Social $\mathrm{ABCs}$, but that with time, the intervention became "second nature" and feasible in their daily routines as a family.

Ruby: In the beginning it was like homework for me where...I'd do it really when he was stuck in one room...because it was easier for me... I mean it's more natural now, when we're getting ready to go out or if he's in the kitchen and wants something... then I'll do it and it is much more natural. 
Judy: ... so it didn't interfere in the sense that it was something for me to get used to, like anything else in the beginning I had to get used to doing it a certain way... but then it just came more natural.

Major accommodations required. In contrast to the above responses, one family (two parents) reported that they experienced a significant shift in focus from work to the intervention in order to accommodate the Social ABCs into their daily routines as a family. Specific changes were required in their daily routine including scheduling time during the day to implement and practice the Social ABCs, as well as reducing the time the child spent on her own. The mother emphasized that these changes in their daily routines were required in order to help her child.

Tom: Well we try to set up a schedule in a way that would allow us to spend some time with Ava... Mary: Ya you had to dedicate your schedule and kind of take it away from work.. Tom: Ya my schedule was basically part-time work and the other time was all around Ava's therapy... Mary: and that was a big change because before that Ava was always the kind of girl that we'd leave her on her own for a really long time, she doesn't mind at all.. so Tom really had to shift his focus during the training... you have to change your schedule in order to move forward to make it work.

Impact on parent-child interactions during routines. An interesting and unique perspective was shared by one mother who reported that it was not her daily routines that were affected by the Social ABCs, but rather, the way she interacted with her child throughout her daily routines changed.

Ellen: Ya, ya... it changed... I have to change... we have to change and then let him to ask for something instead of I just give him automatically... being a mom, I have to change myself in order for Ben to change.

\section{Theme 4: Feasibility of Social ABCs Implementation}

The theme of feasibility emerged as an important component of the lived experience of the Social ABCs. This theme was defined as the ease or convenience of implementing the Social ABCs intervention throughout daily routines, captured by parents' comments on how "easy" it was to incorporate the Social ABCs into their daily lives. This theme included four subthemes: 
the ease of implementation, the involvement of multiple family members, the challenge of training spouses, and the continued use of the Social ABCs beyond the study phase. Involving siblings in the intervention and the use of the Social ABCs strategies following completion of the study highlights the feasibility of the intervention, such that it is easy to teach siblings, and the strategies can be maintained beyond the completion of the research study. The challenge of training spouses highlights the significance of the training coming from outside the marriage. The subtheme of family accommodations to daily routines (discussed above) could arguably fit under the theme of feasibility, as it speaks to how well the Social ABCs intervention fits into the family's daily routines. However, the probes about family accommodations were generated from the literature on Family Quality of Life, and therefore are also felt to fit well into the theme of "Impact on the Family System" above. The subtheme of family accommodations is therefore not repeated here, but may be worth consideration within the construct of feasibility.

Ease of implementation. A common subtheme that emerged from the interviews was the parents' descriptions of the Social ABCs as "easy" to implement and integrate into their daily lives with their child and family.

Anne: ... for having a busy life it was like just a perfect study to kind of like put it to implement, with my husband, with my daughter, with myself, so we just found it was a very very easy thing to do, it's really common sense... it's something that anyone can do.

Leah: ...it was very very positive, very easy.

In contrast, one parent highlighted the initial unexpected difficulty of implementing the Social ABCs intervention, which, with time, became "second nature".

Ruby: It was challenging... because ...it just seems so common sense and straightforward but really it is very controlled and you have to be very... specific in the way you... carry out the actual like the way you do it... it was just more challenging than I expected... because in the beginning it is contrived it is like you almost think ahead and sometimes thinking ahead I would fumble... whereas eventually I realized ok relax and then it became and now it is second nature... now I don't have to think about it. 
Family involvement. Some parents reported that multiple family members were involved in the implementation of the Social ABCs strategies. From spouses, to siblings, to cousins and extended family members, parents highlighted the significance of involving the family as a whole in the Social ABCs intervention.

Anne: It has made a huge difference, I mean my husband got involved in it as well, my daughter, my four year old daughter picked up on it very quickly... she [older daughter] would see us doing it, and ...she wanted to be involved, like this is a great opportunity, they're playing together and they can do that...we would teach her how to do it ... it was almost as if anyone can do it, I mean you can get a four year old, or the sibling to help them, umm and guide them through it...

Judy: Actually, well I was the one being trained on it, and I was trying to like train as best as I can my husband... and I noticed one of my sons, I didn't teach him, but he was trying to imitate me... and he realized what I was doing and he would try it. So I think it was the same, a consistent thing now from all of her immediate family members.

Challenge of training spouse. Some parents mentioned the difficulty when trying to

educate and correct their spouse in the implementation of the Social ABCs strategies, in turn, highlighting the importance of training coming from outside the marriage.

Mary: ...if one of us was doing something wrong and the other one called them on it, that was not easy... but it was easier than without the training. So it's always good to get that reinforcement like where they would be coming back every once in awhile so if you did slip back into bad habits, as soon as the coaches came out again, they would be able to get you on the right track again.

Ruby: I've talked to our nanny and my husband, sometimes I'll give a little bit of direction but I don't want to do too much because then it almost seems like I'm reprimanding saying "stop, no you need to wait" and I catch myself doing it...it is hard as a spouse to educate your other spouse or correct them, when it is a third party you have no issue when they come and say you're doing it wrong or could you try it this way or don't speak so much, when it is a spouse saying it to another spouse sometimes it comes across as you being critical and it's not healthy, so it's not worth doing it. 
Continued use of Social ABCs. Several parents reported that they have continued to implement the strategies they learned during the Social ABCs intervention beyond the completion of the study.

Judy: once the study was finished, I was actually encouraged to continue doing things like that with Quinn...

Anne: ... we still do it today, like we just do it because we've been doing it for so long so why not, it's just gonna work, and gonna keep the words coming.

Tom: Actually we are still... implementing some of the exercises I learned...we are still practicing some of what we learned and I found it very useful still... we are still doing it, even if we're not doing it officially as a main therapy for Ava, it is something that we are still practicing and doing with her.

\section{Theme 5: Reflections on the Social ABCs Experience}

The final theme that emerged from the interviews was parents' reflection about their Social ABCs experience. Based on parents' comments, this theme was defined as parents' reflections about the Social ABCs intervention itself, and their overall experience in the intervention. Within this theme, two subthemes emerged: feedback about the Social ABCs intervention model; and parents' positive feelings about their participation in the intervention.

Feedback about the Social ABCs intervention model. Several parents made comments about the structure, scheduling, and curriculum associated with the Social ABCs intervention and/or participation in the Social $\mathrm{ABCs}$ research study. For the most part, these comments were very positive, but a few comments highlighting the limitations of the intervention were shared.

Anne: I just think the study in itself is just it's brilliant, it's very simple, and just brilliant, it could be done by anyone, anyone can do it...

Ruby: I thought the intervention was great... I would have liked it to be longer... just to oversee it longer... it is an empowering tool.... It has really helped us!

Ellen: So I think that that study, the training one on one is good, one parent and the trainer is good, and then we have time to practice so I think overall it's good... maybe the earlier the better, so... we can learn the skills earlier to help Ben earlier and then he can 
get the benefits from it.

Judy: I did find it beneficial... again I know what the goal of the study is, we didn't meet the goal, but in a way we did, we still got something out of it.

Leah: I would recommend it to anybody with kids under the age of 2 and that's that.

Although most of the feedback about the Social ABCs intervention model was positive,

Tom and Mary presented a unique perspective on the limitations of the Social ABCs curriculum.

These limitations are important to acknowledge as they created difficulties for this family during their Social ABCs experience. One of the two limitations was finding exercises to implement with their child once she had mastered the developmental expectations set out by the Social ABCs intervention.

Tom: I think it was a very good therapy... at the end we were still implementing but we kinda reached the point that Ava was kinda mastering all the exercises that we were implementing with her... Mary: ya we didn't know where to go from there...

The second limitation highlighted by the same family was with regard to the absence of incorporating discipline in the Social ABCs curriculum.

Mary: We had a big issue too... it was our primary issue with that training is that there was no way to incorporate discipline... that was the big difference we saw between when she was receiving IBI and PRT, is that everything was on her own terms, and that's one of her biggest challenges, or our biggest challenge with her is, is that as long as everything is on her own terms she's good... And also when we needed her to do things, like life things that do require discipline, we were completely lost at what to do.

Positive feelings about participation in Social ABCs. All parents expressed overall

positive feelings regarding their participation in the intervention.

Anne: We were so so happy to be part of it... it was a pleasure to be part of it... pleasure... absolute pleasure... it was a very very positive experience for us.

Ruby: I really enjoyed having somebody trained in it to come and just tweak it for me, I enjoy the feedback because I want to learn... I felt very lucky to be given the option... to learn it and use it... It was great!... It was a great experience. 
Judy: I'm just really happy I did this study... I'm happy we did it because it also opened up different types of speech... I think I've gained something from all of this too, so I'm quite happy!

Leah: Overall it was a very positive experience and that's really it!

\section{Summary of Findings}

In summary, five major themes emerged and/or were elicited from the interviews, including a variety of ways in which the Social ABCs had an impact on the child, the parent, and the family as a system. Themes of child gains in communication and engagement, of parent skill acquisition and increased hopefulness, and of family-based changes including reduced stress and improved family relationships, all reveal the complexity of the impact on the family of this parent-mediated intervention for toddlers with ASD. Reflections that were more directly related to the characteristics of the intervention included themes of feasibility of implementation, and overall comments about the Social ABCs model and experience. The next section (Discussion) will focus on these themes in the context of existing literature to illuminate similarities as well as novel contributions to this research area. 


\section{Chapter 5: Discussion}

This study explored the lived experience of families involved in the Social ABCs parentmediated intervention for toddlers with ASD. In light of the paucity of studies evaluating family outcomes of parent-inclusive interventions for children with ASD, the aim of this study was to gain insight into the impact of the Social ABCs parent-mediated intervention on the family as a system. Therefore, the research question was: What is the lived experience of families involved in the Social ABCs parent-mediated intervention? To answer this question, the methodological design of this study was influenced by phenomenology and guided by literature on family outcomes associated with early intervention for children with disabilities. Findings from this study were both consistent and inconsistent with existing research. The current findings illustrate the impact of the Social ABCs parent-mediated intervention on the child, parents and the family, highlighting the unique contributions of this work, and future directions for this line of research.

For the purpose of this discussion, the five themes that were identified from the interviews will be highlighted and discussed in the context of existing research. The five themes include: impact on child; impact on parents; impact on the family system; feasibility of Social $\mathrm{ABCs}$ implementation; and parents' reflection on the Social ABCs experience.

\section{Theme 1: Impact on Child}

All of the parents in the current study highlighted the impact that the Social ABCs intervention had on improving their child's development, specifically in the areas of their child's communication and engagement. This theme was pervasive within and across interviews, initially emerging from the first question, being elicited in subsequent direct questions, and recurring again from the concluding summary question. 
Parents' observations of their child's improved communication skills from having participated in the Social ABCs intervention is consistent with findings from an existing exploration of a parent-mediated intervention aimed at promoting communication in toddlers with ASD (Schertz \& Odom, 2007). In Schertz and Odom's (2007) qualitative analysis (in addition to their single subject design), parents reported that their child's language skills had improved post-intervention. Parents' emphasis on their child's communication gains as an outcome of interventions targeting communication skills is further evident in parents' experiences of running home-based EIBI and ABA programs (Trudgeon \& Carr, 2007; Grindle et al., 2009; McConkey et al., 2010).

The subtheme of children's improved communication development is also consistent with quantitative analyses of parent-inclusive models of intervention targeting communication outcomes for children with ASD (Koegel et al., 1996; Bryson et al., 2007; Smith et al., 2010; Coolican, Smith \& Bryson, 2010; Fava et al., 2011; Strauss et al., 2012; Roberts et al., 2011; Ingersoll \& Wainer, 2011; Dawson et al., 2009). However, unlike quantitative studies that may not capture sub-clinical subtleties in children's developmental gains, the current qualitative exploration highlighted an appreciation of even the smallest changes in children's communication skills. For example, one mother reported that, although her goal for her daughter to speak was not fully met during or since the Social ABCs, she was still "content that there was still some progress in there [italics added for emphasis]" with her daughter's increased vocalizations.

Of particular significance in the current investigation, parents emphasized that their child's communication gains made a positive difference not only in their child's life, but also for the family as a system. This important insight, which is consistent with family systems theory, 
might have been missed had we employed solely quantitative measures of child outcomes to evaluate the Social ABCs intervention.

Although not raised by all parents, some parents did comment on improved engagement in their child as a result of their involvement in the Social ABCs. The issue of engagement has received considerably less attention in intervention studies, but is nonetheless an important consideration in this population.

\section{Theme 2: Impact on Parents}

Participation in the Social ABCs clearly had an impact on the parents as well as on the child. A variety of domains in which improvements took place were identified during the interviews. For example, parent responses indicated improvements in parents' acquisition of skills to interact and help their child learn, and in parents' hopefulness for their view of the future for their child. The theme of 'impact on parents' consistently appeared in response to all questions, highlighting its predominance in the lived experience of families involved in the Social ABCs intervention. This theme is especially relevant in the context of parent-inclusive interventions, as parent training, education and involvement have been shown to positively impact not only the child, but also parents (McConachie \& Diggle et al., 2007).

The impact of the Social ABCs intervention on parents' knowledge and skill acquisition is consistent with other studies of parent-inclusive interventions for children with ASD (Patterson \& Smith, 2011; Granger et al., 2012). Similar to reports from parents in the Social ABCs that they acquired skills to help their child learn, parents in the parent-mediated More Than Words program also reported that they learned skills to help their child (Patterson \& Smith, 2011). With the aim of identifying forms of parent involvement in EIBI, Granger et al., (2012) found that mothers reported that acquiring knowledge was one form of their involvement in their 
child's EIBI program, among many others. However, these mothers specified that the knowledge gained was specific to the intervention, rather than to their child.

In contrast, some studies of parent-inclusive interventions have reported mixed results regarding parents' knowledge acquisition. For example, Roberts et al., (2011) found that parents in the experimental group (a centre-based program with parent training and a support group) showed a statistically significant difference in their perceptions of their knowledge and understanding of ASD post-intervention, compared to parents in an individualized home-based program and a non-treatment control group (parent training was not provided). On the other hand, Oosterling et al., (2010) found no significant differences in parents' skill improvements between their experimental group (non-intensive parent training with care-as-usual) and a control group (care-as-usual), concluding that a parent-training component did not provide any additional value (in terms of parental skills).

Parents in the Social ABCs highlighted the impact this experience had on their view of the future for their child, indicating that their hope for their child's future had improved. Schertz and Odom (2007) reported a similar finding that parents' views of their child's potential had evolved with their participation in a parent-mediated intervention targeting joint attention in toddlers with autism.

While the issue of parental stress has largely dominated the literature examining parent outcomes of parent-inclusive models of ASD intervention (Fava et al., 2011; Ingersoll \& Wainer, 2011; Strauss et al., 2012; Bendixen et al., 2011; Roberts et al., 2011), it is noteworthy that parents in the Social ABCs did not, with the exception of one parent, raise the topic of stress until they were probed to do so specifically. This suggests that the issue of stress may not be as salient in this context as presumed, especially relative to other topics (e.g., children's improved 
communication), or may not be the most appropriate index to capture the impact on parents of participating in a parent-mediated intervention. It remains possible, however, that the issue of parent stress did not emerge spontaneously due to the context of the study; the author was not well known to the families prior to the interview, and thus parents may not have been comfortable offering comments on the topic of stress so early in the interaction. Findings specific to the topic of stress will be discussed in the following theme.

\section{Theme 3: Impact on the Family System}

Family quality of life has been conceptualized by Bailey et al., (2006) as "an ultimate goal" of early intervention programs (p. 243). Proposed as an appropriate index of outcome for families of young children with disabilities receiving early intervention services (Epley et al., 2011), family quality of life refers to 3 topics that have been highlighted as primary impacts of a child's disability on the family: family stress; family functioning; and family accommodations to daily routines (Summers et al., 2005). These topics were directly probed in the current interviews, eliciting meaningful subthemes relevant to the impact of the Social $\mathrm{ABCs}$ on the family as a system.

Half of the families expressed that the Social ABCs had an impact on their family as a system, reporting improvements within the family in terms of stress and frustration, time spent together, relationships, and communication. In two studies evaluating the impact of home-based interventions on families of children with ASD, Trudgeon and Carr (2007) and McConkey et al., (2010) reported similar findings that parents felt the "family as a whole had benefited" from the intervention (McConkey et al., 2010, p. 307)..

Family stress. Almost all of the parents, with the exception of one, emphasized that the Social ABCs intervention had reduced their family stress. It is important to highlight that the one 
parent who did not report a decrease in family stress, in fact reported feeling an increase in stress at the beginning of the Social $\mathrm{ABCs}$ intervention, "because you're going through a new therapy... you didn't know if it was going to work", but that the stress subsequently decreased "because you knew that your techniques actually were making a difference". Some parents, in addition to stating that their stress had decreased due to their participation in the Social ABCs, also commented that they experienced an increase in stress when their child was diagnosed with ASD, consistent with the literature highlighting the impact of the ASD diagnosis on family stress (Karst \& Van Hecke, 2012).

This finding that the Social ABCs improved the stress levels for most of these families offers a unique contribution to the literature, as the majority of existing studies that have explored the effects of parent-inclusive interventions on stress have shown mixed results. While some studies reported a significant decrease in stress for parents (Bendixen et al., 2011; Ingersoll \& Wainer, 2011), others reported that parental stress remained relatively stable in the intervention group (Roberts et al., 2011; Strauss et al., 2012). Williams and Wishart (2003) found equivocal family stress levels across parents' experiences of the Son Rise Program implemented by parents, contrasting the present findings. Another trend has been a significant decrease in stress for parents involved in eclectic control groups, but not for those in the parentinclusive interventions (Fava et al., 2011; Strauss et al., 2012), suggesting that parents who were less involved in the provision of the intervention felt less stressed compared to parents who were required to be more involved. These mixed findings emphasize the need to explore parental and familial stress from a variety of perspectives, using multiple methods, in order to elucidate and gain a better understanding of some of these inconsistencies. 
Family functioning. The majority of parents reported improvements in the relationships and dynamics within their family that they related to their participation in the Social ABCs. This exploration of the impact of the Social ABCs intervention on family functioning is not only unique to the ASD literature, but it also contributes to the limited existing studies using family outcomes to evaluate the impacts of supports and services for children with disabilities on families (Summers et al., 2005). One notable study is Bendixen et al.,'s (2011) evaluation of the impact of a father-based parent training early intervention program on family functioning. Although results indicated that there were no significant differences in fathers' or mothers' scores on the FACESII following intervention, family functioning is nonetheless important to assess given the potentially influential role that parent training can have on the family system.

Trained parent and child with ASD. The majority of trained parents expressed that their relationship with their child with ASD had improved, which they attributed to their participation in the Social ABCs. This finding is consistent with parent report from one study of a home-based EIBI program interested in the impact of EIBI on family relationships (Grindle et al., 2009). Grindle et al., (2009) found that parents reported an improvement in their relationship with their child with autism. Williams and Wishart (2003) found that parents implementing the Son-Rise program reported that their involvement in the intervention helped interactions between family members, including feeling closer, more accepting, and less judgmental. In contrast, one mother from the Social ABCs reported no changes in her relationship with her son, which she explained was due to the Social ABCs being "second nature" and not likely to have "impacted him in a negative way", illustrating that she may have interpreted this probe to mean change as a negative. 
Non-trained parent and child with ASD. Although one parent reported that her husband's understanding of their child with ASD had improved, which is consistent with parents' experiences in a home-based EIBI program (Trudgeon \& Carr, 2007), most parents reported that there were noticeable changes in the child with ASD that in turn impacted the child's relationship with the non-trained parent. One unique example was illustrated during the dyad interview, where the non-trained parent could not recall if or how her relationship with the child had changed, and it was the trained parent who reminded her that the child was showing increased interest in her with the implementation of the Social ABCs strategies. This illustrates a benefit of interviewing parents as a dyad, such that parents can help one another with memory recall, thus, enriching each other's insights.

Parents' relationship. Almost all of the parents (including the dyad) expressed that the Social ABCs had improved their marriage (with the exception of two parents who reported that it did not impact their marriage either positively or negatively). This finding significantly differs from parents' experiences in home-based EIBI programs (Trudgeon \& Carr, 2007; Grindle et al., 2009). While Trudgeon \& Carr (2007) found that parents reported mixed effects of the program on their marriage (closeness, breaking up), parents in Grindle et al., (2009) expressed that the relationship with their spouse had "deteriorated", often as a result of spending less time together. No parents reported that they experienced any improvements in their relationship as a result of the EIBI program (Grindle et al., 2009). This is a striking contrast to parents in the Social ABCs who commented on improvements such as, "we're not arguing as much as we were before... our marriage has gotten better", and "because we have the study together... the more time we spent together... our relationship is better". In the dyad interview, the only trained father, made an insightful and unique comment about his relationship with his wife during the Social ABCs 
intervention: "we worked like a team and we did very well, and it was a good interaction". These comments highlight the value of employing qualitative methods to better understand family relationships. It is notable that parents in the Social ABCs reported improvements in their marital relationship that were not reported by parents in the EIBI study. Although these findings are preliminary, it is conceivable that naturalistic, parent-mediated interventions may be more "family-friendly", thus resulting in improved family relations when compared to interventions that do not directly involve parents.

Child-sibling relationship. Four families had at least one older sibling in addition to the child participating in the intervention. Of those, three reported that the relationship between their child with ASD and his/her sibling(s) had improved as a result of the child's improved communication and social interactions. For example, some parents reported improvements in the child's relationship with his/her sibling in terms of play and engagement, whereas some reported that their child's communication gains led to improvements in the sibling relationship: "they always got along, again but just because of where Will's communication level is now, they're the best of friends". This finding is consistent with reflections from parents in home-based EIBI programs interviewed by Trudgeon \& Carr (2007) and Grindle et al., (2009) who reported that the sibling and child relationship improved, specifically with regard to their ability to play together. In addition, some parents in the current study reported having taught their older child some of the strategies of the Social ABCs intervention. This will be discussed in the theme "feasibility".

Parent-sibling relationship. While none of the parents reported any observable changes in their relationship with their other children, two parents commented that they spent more time with their older child due to participation in the Social ABCs. This is a striking contrast to 
parents' experiences of home-based EIBI programs and the Son-Rise parent-implemented program (Williams \& Wishart, 2003; Trudgeon \& Carr, 2007; Grindle et al., 2009). Across these three studies, parents reported that they had less available time to spend with siblings of their child with ASD, which for families in Grindle et al., (2009) resulted in some parents feeling that their relationship with the sibling had "deteriorated", and for families in Williams \& Wishart (2003), parents reported that it sparked jealousy and upset from the siblings. Although parents in the Social ABCs did not report similar conflicts, a few parents did mention the initial challenge for siblings when the child with ASD received specialized attention from the Social ABCs trainers in the home. Some parents also reported that the sibling was out of the house while the Social ABCs training occurred, and this could be a possible explanation for why the parentsibling relationship was not negatively impacted to a similar extent as highlighted by parents in the home-based and Son-Rise programs. Furthermore, two parents emphasized that they taught and involved the older siblings in the Social ABCs, which will be discussed in the theme, “feasibility", below.

Parent as interventionist. To further explore parents' experiences adopting the dual role as parent and trainer in the Social ABCs intervention, an unplanned probe asked parents to comment on their experience with this dual role. From parents' responses, a range of comments were identified as "natural"; "challenging"; "empowering".

Four of the seven parents described their experience as parent and trainer to be "very, very natural", "very kind of normal" and something "just incorporated". These comments echo parents' earlier responses to the family accommodations to daily routines probe, further highlighting the feasibility of parents' adopting the role as trainer for the Social ABCs 
intervention, which may reflect the benefit of employing naturalistic behavioural principles for families of young children with ASD.

The current finding regarding parents' "natural" experience of adopting the dual role as parent and trainer in the Social ABCs is novel and insightful. Existing literature of parentinclusive interventions has found that the experience for parents has been more negative than positive (Granger et al., 2012). For example, in a study of parents' experiences in parentinclusive EIBI programs, Granger et al., (2012) found that parents often perceived these roles as "incompatible" and "emotionally difficult", emphasizing that mothers who were implementing the EIBI program expressed many barriers to adopting the role of therapist as well (p. 73-74). These barriers included fatigue from implementing the intervention, reduced time spent with other children in the family, and a change in the parent-child relationship, such that their status as mother prevented them from being as effective at working with their child compared to the therapist.

Parents in the Social ABCs also reported some challenges with this dual role, although their responses differed from those reported elsewhere (e.g., Granger et al., 2012). Some parents reported feeling frustrated when trying to teach their child, pressured with the sole responsibility to implement this program, and difficulty with some of the specific techniques (e.g., changing the interactions between the parent and child to require a response from the child). While the parent trainer role in the Social ABCs experience was "challenging" for some parents, there were no reports similar to the mothers in Granger et al., (2012) of feeling "greatly relieved about no longer having to play a dual role" (p. 73). Interestingly, one mother in the Social ABCs expressed that her role as trainer powerfully contributed to her son's improved communication, so much so, that his communication gains might not have been as pronounced if a third party had 
implemented the Social ABCs strategies: “... as a parent I think they're more motivated by you interacting with them... I don't know if the success rate would be as high as if your own mother or father were doing it". This finding highlights the significance and impact of the parent trainer role not only for the child, but also, for parents.

Unique to one mother, who commented that she felt "pressured" and unsupported in the implementation of the Social ABCs, she also emphasized that the Social ABCs was "empowering" for her, as it provided her with a tool she could feel good about using with her son. This is consistent with reports from some parents in Trudgeon and Carr's (2007) study who reported feeling empowered from running a home-based EIBI program.

The overall positive experiences of adopting the role of parent and trainer in the Social ABCs stands in contrast to reports from more structured EIBI programs. Although our findings cannot be extended beyond the current participants, this difference may be a reflection of the nature of the different interventions. While the Social ABCs is naturalistic and intended to be implemented throughout the day using natural reinforcers to motivate children's language development, EIBI is typically more structured, more intensive, and implemented at specific times throughout the day, often using artificial reinforcers. It is worth considering the possibility that the more naturalistic approach of the Social ABCs contributed to this positive experience. Parents highlighted the importance of their own feelings of efficacy as therapists, reflecting that their interactions impacted the child's developmental outcomes, which then impacted the family as a whole, consistent with family systems theory. These findings should be closely considered with regard to parent-inclusive interventions for children with ASD, as it is important to recognize the overall impact on the family for parents adopting the trainer and parent role. 
Family accommodations to daily routines. Parents reported common, yet somewhat variable, comments regarding the accommodations in families' daily routines that were required as part of the Social ABCs intervention. While two parents reported that the Social ABCs did not require accommodations, as the intervention was easily incorporated into their existing daily routines as a family, two parents reported that initial accommodations were required, but that with time, the Social ABCs became "second nature" and feasible within their existing daily routines. These findings are especially significant in light of the argument by Bernheimer and Weisner (2007) that "no intervention, no matter how well designed or implemented, will have an impact if it cannot find a slot in the daily lives of an organization, family, or individual” (p. 199).

These findings stand in contrast to existing findings from home-based (therapistdelivered) intervention programs (Trudgeon \& Carr, 2007; Grindle et al., 2009). Parents in the Trudgeon \& Carr (2007) study, for example, reported that they had to reorganize their home environments to accommodate space for the child's workroom. They also expressed that tutors' presence working in the home imposed on family privacy. Similar findings that highlight the impact of the program structure on daily routines have been highlighted by Grindle et al., (2009). Interestingly, parents expressed that "the increased emphasis of natural environment teaching" (p. 48) in their child's EIBI program, which resulted in less structured table-top work, caused parents to feel as though their privacy in private spaces such as the bedroom was lost for the family. In addition, some of the parents emphasized that the presence of therapists in the home further reduced privacy and interrupted their domestic daily routines (e.g., having to be home at the start and end of each therapy session).

With the aim of identifying forms of parent involvement in EIBI, Granger et al., (2012) found that all mothers reported the daily implementation of EIBI principles as one form of their 
involvement in their child's program. According to the author, the mothers appeared to have applied and assimilated the principles into their daily routines, though they did clearly differentiate between "everyday generalization of acquisitions and more formal application of EIBI to develop new skills in their child", with the former being the focus of mothers' implementation in daily routines, which may explain the differences across parent report in these three EIBI studies (p. 73).

Although the majority of parents reported that minimal accommodations were required to implement the Social ABCs, one family (both parents present) expressed that major changes in their work lives were required to accommodate their participation in the research study:

Mary: You [dad] had to dedicate your schedule and kind of take it away from work... Tom: Ya my schedule was basically part-time work and the other time was all around Ava's therapy... that was the changes that we did and the kind of adjustment that we had to do.

This same family later addressed the challenge of parenting a child with ASD, working full time jobs, and participating in their child's intervention (not Social ABCs specific), highlighting that the needs and circumstances of working parents need to be addressed by early intervention providers:

Mary: ... for parents that are working come up with a different offering for them. Like I said, parents have to be involved either way like I said, but maybe there would be a better way for two working parents to be able to help their kid... there should be different things to different types of families.

This finding reflects similar working parents' experiences in the More Than Words program (Patterson \& Smith, 2011), which concluded that, for parents who work outside the home, interventions need to consider working parents' unique needs and schedules. Parents, specifically fathers, in the More Than Words program felt they had missed out on the coaching and felt left out. It should be noted that because the Social ABCs intervention phase was part of a research 
study that required one parent to stay home with the child $50 \%$ of the time over the six month study period, this may have had a greater effect on family accommodations to daily routines compared to implementing the Social ABCs without having been part of the research study (i.e., private training in the Social ABCs techniques). This should be explored in future studies of parent-mediated interventions that have different requirements of parents' time.

\section{Theme 4: Feasibility of Social ABCs Implementation}

Within and across the interviews, parents repeatedly commented on the feasibility of implementing the Social ABCs intervention, which was defined as the ease and convenience of implementing the intervention. This theme included four subthemes: the ease of implementation, the involvement of multiple family members, the challenge of training spouses, and the continued use of the Social ABCs beyond the study phase. This theme emerged in response to the introductory and final questions, and was elicited in response to question \#2 and across probes, specifically probes 4 (role as parent and trainer) and 5 (changes in daily routines).

Ease of implementation. Although this subtheme has been highlighted in the subtheme of family accommodations to daily routines (which pertains to a component of family quality of life), it is especially relevant to the theme of 'feasibility' and is thus included here as well. As previously noted, most parents expressed that the Social ABCs was "easy" and "second nature" to incorporate into their existing daily routines as a family. For example, Anne commented, "it's something simple to do, and ... it doesn't affect your whole life, like you can do it at any time". As highlighted earlier, this finding is not common across behavioural interventions for children with ASD (with or without parent components), and therefore is a unique finding, especially in light of the argument that for an intervention to be effective it "must fit into the existing beliefs and practices already in place" (Bernheimer \& Weisner, 2007, p.199). This suggests that the 
foundational role of parent and trainer in the Social $\mathrm{ABCs}$ intervention may be significantly unique to parent-mediated models of intervention for children with ASD.

Family involvement. From spouses, to siblings, to cousins and extended family members, some parents highlighted the significance of involving the family as a whole in the implementation of the Social ABCs intervention. For some families with older siblings, some parents reported that the older sibling "picked up on it [Social ABCs] very quickly" and "wanted to be involved". While some parents mentioned explicitly teaching the older sibling the Social ABCs strategies, others reported that they noticed that the sibling learned the strategies by modeling the parents. For example, one mother commented, "I noticed one of my sons, I didn't teach him, but he was trying to imitate me... and he realized what I was doing and he would try it". This highlights an invaluable opportunity for the child with ASD to learn language through play with his/her sibling in a natural setting, and in turn, consistent with family systems theory, is likely to impact the child's relationship with the older sibling. Furthermore, it illustrates the feasibility of implementing the Social ABCs intervention, to the extent that even young children (average age of 4) can learn, imitate and use the Social ABCs strategies relatively easily to prompt expressive communication from their younger sibling with ASD. These findings stand in stark contrast to comments made by parents in a more traditional home-based EIBI program, who reported that the sibling was typically "banned" from entering rooms when the therapy was occurring (Grindle et al., 2009, p. 48).

Challenge of training spouse. A few of the trained parents (including the dyad) commented on the challenges of training, educating and correcting their spouse in the implementation of the Social ABCs intervention. This subtheme was elicited in response to question 3 and emerged in the concluding question. The consensus expressed by parents was that educating and correcting 
their spouse was "not easy", but that "when it is a third party, you have no issue". This finding is relevant to the theme of feasibility because, while it was "easy" and "natural" for the parents to implement the Social ABCs strategies with their child, training their spouse proved to be more difficult. This finding is consistent with parents' experiences in the More Than Words program, whereby parents reported that their partners who had attended the educational sessions felt responsible for communicating the information and training to them (Patterson \& Smith, 2011). Future research would benefit from considering this issue further, with the purpose of exploring ways to maximize the role of the non-trained parent, so they too can implement the strategies and better support the trained parent so that he/she does not feel as one mother in the Social ABCs reported, "it is just me doing most of the work".

Continued use of Social ABCs. Several parents reported that they continue to implement the Social ABCs strategies in their present daily lives. These parents emphasized that although the intervention study was complete (recall that there was an average time lag of 9 months since their completion in the intervention), they continue to implement the skills and strategies they learned from the Social ABCs. For example, one parent remarked, “... we still do it today... it's just gonna work, and gonna keep the words coming", and another parent commented, "even if we are not using it right now, let's say officially, we are still practicing some of what we learned and I found it very useful still”. Continued implementation of the Social ABCs strategies further highlights the feasibility of the intervention for families, and the families' satisfaction with the strategies. Trudgeon and Carr (2007) reported a similar finding in that parents reported applying the knowledge they learned from the home-based EIBI programs into "all walks of life" (p. 294). 


\section{Theme 5: Reflections on the Social ABCs Experience}

The current phenomenological exploration of a parent-mediated intervention (the Social $\mathrm{ABCs}$ ) provided a unique opportunity to gain the first-hand perspectives of families participating in the program. The final theme to emerge from the interviews was parents' overall reflections about their Social ABCs experience. Within this final theme, two subthemes emerged: feedback about the Social ABCs intervention model; and parents' positive feelings about their participation in the intervention.

Although parents described the limitations and challenges they experienced with the Social ABCs intervention model, parents almost always returned to reflections of their overall experience, which they all reported as having been "positive". A similar finding of an overall positive experience in spite of practical and emotional challenges was reported by parents running an EIBI home-based program (Grindle et al., 2012). To the author's knowledge, there are no other studies of parent-inclusive interventions that have generated overall positive reports from parents. However, the current finding of an overall positive experience reported by all families should be interpreted with some caution. Specifically, it should be considered in light of the possibility that parents' overall positive experience may reflect a positivity bias; parents' positive experiences may have been in response to parents' relief due to receiving any early intervention services rather than a reflection of parents' overall satisfaction with the Social ABCs intervention itself. Zellman and Perlman (2006) found that measures of parent childcare involvement often yield uniformly positive parent responses despite evidence of significant problems with the childcare provider. Similarly, parents' experiences of the Social ABCs may have been influenced by factors not specific to the Social ABCs (e.g., receiving professional attention, receiving any early intervention), and thus may not fully capture the variability in the 
lived experience of the Social ABCs intervention and should not be misinterpreted as a positive evaluation of the efficacy of the Social ABCs intervention.

\section{Limitations and Future Directions in Research}

The present study was not without limitations and these should be acknowledged.

First, most of the participants were mothers trained in the Social ABCs intervention, with the exception of one dyad, which was comprised of a trained father and a non-trained mother. It should be noted that the author invited and encouraged both parents to participate, however, this was impractical for most families, resulting in a greater number of female trainer perspectives represented in the current study. While there were no overt differences in the perspectives of the trained father and the trained mothers in the current study, future explorations of parent-mediated interventions should strive to represent the perspectives of both mothers and fathers from the trained and non-trained role, as well as children with ASD and their siblings, in order to reflect the families' collective perspective and experience regarding the impact of the intervention on the entire family.

Second, it is possible that the overall positive experience expressed by parents represents a positivity bias (Zellman \& Perlman; 2006, as discussed above) or a sampling bias; specifically, it is possible that participants who were more satisfied or experienced more success with the intervention were more likely to agree to participate in the current study and share their experiences. However, of the five families who were approached but who did not participate, two said they were interested but too busy at the time, suggesting that it may not have been their satisfaction or perceived success with the program that hindered their participation. Future studies would benefit from interviewing families who do not complete, or who withdraw from intervention programs, with the aim of gaining an understanding of their family experience, and 
whether they differ in any systematic ways from the families' experiences reflected in the present findings.

Third, the length of delay between families' completion of the Social ABCs intervention phase and parents' participation in the present study averaged 9 months for the majority of families (range: 3-19 months), with the exception of one family who had completed the intervention phase 27 months prior to the interview. This raises the possibility that other interim factors, unrelated to the Social ABCs, may have influenced parents' responses (e.g., developing an increasingly positive perspective after increased child gains post-intervention). Future studies would benefit from interviewing families soon after the completion of the intervention to reduce the potential for unrelated factors to influence parents' reflections on their experiences. However, the perspectives from the current study do give insight about the longer-term impact, which is also of value and should be retained in future studies (i.e., interviews could be conducted at multiple time points).

Finally, because this study used a phenomenological approach, the findings are limited with respect to their generalizability and representativeness of the larger population. However, the phenomenological approach was used to guide this exploration because of its ability to provide a rich portrait of families' lived experience in the Social ABCs intervention, a goal which would not have been achieved using the quantitative measures currently employed in the larger Social ABCs study. By identifying themes expressed by multiple respondents, the author is confident that the current findings provide insight into the essence and meaning of the lived experience for families involved in the Social ABCs intervention. 


\section{Implications for Practice}

The lived experience of families involved in the Social ABCs parent-mediated intervention may be useful for informing practice, policy and program development. The current provincially funded intervention for children with ASD (i.e., EIBI) is based on evidence that intensive and structured treatment is effective in improving children's developmental outcomes. However, the current findings demonstrate that the naturalistic, parent-mediated approach taken by the Social ABCs was feasible and acceptable to the families in the present study, and that parents perceived improvements in their children's development, which they felt had a positive impact on the family as a system. It will be important to bolster the current findings with evidence of efficacy (currently under examination through a randomized controlled trial of the Social ABCs). These findings, together with the fact that children with ASD have unique needs that should be addressed by individualized programming, rather than a one-size-fits-all approach, provide support for the consideration of increased access to naturalistic, parent-mediated intervention models as a viable alternative for families of children with ASD. This is especially relevant in light of limited access to, and the high cost of EIBI, research demonstrating that 50\% of children do not respond positively to discrete trial training (a primary application of EIBI), evidence in favour of the importance of early intervention as the best predictor of successful developmental outcomes, and studies highlighting increased parenting challenges and stress for parents of children with ASD, all of which in turn, impact the family as a system. Future exploration of parent-mediated intervention models will need to carefully consider the specific child and family factors that improve the feasibility and effectiveness of this type of intervention program. 


\section{Conclusion}

This study explored the lived experience of families involved in the Social ABCs parentmediated intervention for toddlers with ASD. Overall, the findings highlight the variety of ways in which the Social ABCs had an impact on the child, the parent, and the family as a system. While the author does not claim to have fully captured the "essence" of families' lived experience in the Social ABCs intervention, the ultimate goal of gaining an understanding of families' lived experience in the Social ABCs intervention, and how this lived experience impacted families, was achieved. Five themes identified from parents' perspectives of their families' experience in the Social ABCs are informative in providing insight into the essence and meaning of the lived experience for families involved in the Social ABCs intervention. Preliminary findings from this study provide a rationale for future research exploring families' collective experience in parent-mediated intervention models in order to elucidate the impact on the family as a system from the perspectives of multiple family members. These findings may contribute to the growing evidence base regarding parent-mediated interventions for toddlers with ASD. As such, these findings may help to inform practice, policy and program development related to early intervention for young children with ASD and their families. 


\section{References}

American Psychiatric Association: Diagnostic and Statistical Manual of Mental Disorders, Fifth Edition. Arlington, VA, American Psychiatric Association, 2013.

Bailey, D. B., McWilliam, R. A., Darkes, L. A., Hebbeler, K., Simeonsson, R. J., Spiker, D., \& Wagner, M. (1998) Family outcomes in early intervention: A framework for program evaluation and efficacy research. Exceptional Children, 64(3), 313-328.

Bailey, D. B., Bruder, M. B., Hebbeler, K., Carta, J., Defosset, M., Greenwood, C... \& Barton, L. (2006). Recommended outcomes for families of young children with disabilities, Journal of Early Intervention, 28(4), 227-251.

Barnartt, S. N. (2010). Disability as a fluid state. Washington, DC: Emerald Group Publishing Limited.

Benderix, Y., Nordstrom, B., Sivberg, B. (2007). Parents' experience of having a child with autism and learning disabilities living in a group home. Autism, 10(6), 629-641.

Bendixen, R. M., Elder, J. H., Donaldson, S., Kairalla, J. A., Valcante, G., Ferdig, R. E. (2011). Effects of a father-based in-home intervention on perceived stress and family dynamics in parents of children with autism. American Journal of Occupational Therapy, 65(6), 679687.

Bernheimer, L. P., \& Weisner, T. S. (2007). "Let Me Just Tell You What I Do All Day...” The family story at the center of intervention research and practice. Infants and Young Children, 20, 3, 192-201.

Braun, V., \& Clarke, V. (2006). Using thematic analysis in psychology. Qualitative Research in Psychology, 3, 77-101. 
Brian J, Smith I.M, McCormick T, Dowds E, Longard J.C.P. Roberts S.W, Zwaigenbaum L. and Bryson S.E. "The Social ABCs for Toddlers with Suspected Autism: A Pilot Evaluation of a Parent-Mediated Intervention”. Poster presentation at the International Meeting for Autism Research (IMFAR). May 2012. Toronto, ON.

Bronfenbrenner, U. (1986). Ecology of the family as a context for human development: Research perspectives. Developmental Psychology, 22(6), 723-742.

Brown, R. I., MacAdam-Crisp, J., Wang, M., \& Iarocci, G. (2006). Family quality of life when there is a child with a developmental disability. Journal of Policy and Practice in Intellectual Disabilities, 3(4), 238-245.

Bryson, S. E., Koegel, L. K., Koegel, R. L., Openden, D., Smith, I. M., Nefdt, N. (2007). Large scale dissemination and community implementation of pivotal response treatment: Program description and preliminary data. Research and Practice for Persons with Severe Disabilities, 32(2), 142-153.

Bryson, S. E., McDermott, C., Rombough, V., Brian, J., \& Zwaigenbaum, L. (2008). 'The Autism Oberservation Scale for Infants (AOSI): Scale Development and Reliability Data'. Journal of Autism and Developmental Disorders, 38, 731-738.

Burrell, L. T., \& Borrego Jr., J. (2012). Parents' involvement in ASD treatment: What is their role? Cognitive and Behavioral Practice, 19, 423-432.

Center for Disease Control and Prevention (2012, March 30). Prevalence of autism spectrum disorders - Autism and developmental disabilities monitoring network, 14 sites, United States, 2008. Retrieved October 17, 2012, from http://www.cdc.gov/ncbddd/autism/.

Chawarska, K., Klin, A., \& Volkmar, F. R. (2008). Autism spectrum disorders in infants and toddlers: Diagnosis, assessment, and treatment. New York, NY: The Guilford Press. 
Chasson, G.S., Harris, G.E., \& Neely, W.J. (2007). Cost comparison of early intensive behavioral intervention and special education for children with autism. Journal of Child and Family Studies, 16, 401-413.

Check, J., \& Schutt, R. K. (2012). Research Methods in Education. Thousand Oaks, CA: Sage.

Coolican, J., Smith, I. M., \& Bryson, S. E. (2010). Brief parent training in pivotal response treatment for preschoolers with autism. The Journal of Child Psychology and Psychiatry, 51(12), 1321-1330.

Creswell, J. W. (2009). Research Design: Qualitative, quantitative, and mixed method approaches. Thousand Oaks: Sage Publications Inc.

Dawson, G., Rogers, S., Munson, J., Smith, M., Winter, J., Greenson, J., Donaldson, A., \& Varley, J. (2010). Randomized, controlled trial of an intervention for toddlers with autism: The early start denver model. Pediatrics, 125(1), 17-23.

Donalek, J. G. (2009). The family research interview. Nurse Researcher, 16(3), 21-28.

Eldevik, S., Hastings, R. P., Hughes, C. J., Jahr, E., Eikeseth, S., \& Cross, S. (2009). Metaanalysis of early intensive behavioural intervention for children with autism. Journal of Clinical Child and Adolescent Psychiatry, 38(3), 439-450.

Epley, P. H., Summers, J. A., \& Turnbull, A. P. (2011). Family outcomes of early intervention: Families' perceptions of need, services, and outcomes. Journal of Early Intervention, $33(3), 201-219$.

Fava, L., Strauss, K., Valeri, G., D’Elia, L., Arima, S., \& Vicari, S. (2011). The effectiveness of a cross-setting complementary staff- and parent-mediated early intensive behavioural intervention for young children with ASD. Research in Autism Spectrum Disorders, 5, 1479-1492. 
Flood, A. (2010). Understanding phenomenology. Nurse Researcher, 17(2), 7-15.

Gardiner, H. W., \& Kosmitzki, C. (2011). Lives Across Cultures: Cross-Cultural Human

Development. 5th Edition. Allyn \& Bacon. Boston: MA.

Glynne-Owen, R. (2010). Early intervention and autism: The impact of positivism and the call for change. International Journal of Children's Rights, 18, 405-416.

Granger, S., des Rivieres-Pigeon, C., Sabourin, G., Forget, J. (2012). Mothers' reports of their involvement in early intensive behavioural intervention. Topics in Early Childhood Special Education, 32(2), 68-77.

Greenstein, T. N. (2001). Methods of Family Research. California, USA: Sage Publications.

Grindle, C. F., Kovshoff, H., Hastings, R. P., Remington, B. (2009). Parents' experiences of home-based applied behaviour analysis programs for young children with autism. Journal of Autism and Developmental Disorders, 39, 42-56.

Hoogsteen, L., \& Woodgate, R, L. (2013). Centering autism within the family: A qualitative approach to autism and the family. Journal of Pediatric Nursing, 28, 135-140.

Ingersoll, B. R., \& Wainer, A. L. (2011). Pilot study of a school-based parent training program for preschoolers with ASD. Autism, O(0), 1-15.

Karst, J. S. \& Van Hecke, A. V. (2012). Parent and family impact of autism spectrum disorders: A review and proposed model for intervention evaluation. Clinical Child and Family Psychology Review, 15, 247-277.

Kaslow, N. J., Broth, M. R., Smith, C. O., \& Collins, M. H. (2012). Family-based interventions for child and adolescent disorders. Journal of Marital and Family Therapy, 38(1), 82-100.

Koegel, L. K., Koegel, R. L., Harrower, J. K., \& Carter, C. M. (1999a). Pivotal response intervention I: Overview of approach. The Journal of The Association for Persons with 
Severe Handicaps, 24(3), 174-185.

Landry, S. H., \& Smith, K. E. (2006). Responsive parenting: Establishing early foundations for social, communication, and independent problem-solving skills. Developmental Psychology, 42(4), 627-642.

Lord, C., Risi, S., Lambrecht, L., Cook, E. H., Leventhal, B. L., DiLavore, P. C., et al. (2000). The autism diagnostic observation schedule - Generic: A standard measure of social and communication deficits associated with the spectrum of autism. Journal of Autism and Developmental Disorders, 30, 205-223.

Lovaas, O. I. (1987). Behavioral treatment and normal educational and intellectual functioning in young autistic children. Journal of Consulting and Clinical Psychology, 57, 165-167.

McConachie, H., \& Diggle, T. (2007). Parent implemented early intervention for young children with autism spectrum disorder: A systematic review. Journal of Evaluation in Clinical Practice, 13, 120-129.

McConkey, R., Truesdale-Kennedy, M., Crawford, H., McGreevy, E., Reavey, M., Cassidy, A. (2010). Preschoolers with autism spectrum disorders: Evaluating the impact of a homebased intervention to promote their communication. Early Child Development and Care, 180(3), 299-315.

McWilliam, R. A., Casey, A. M., Sims, J. (2009). The routines-based interview: A method for gathering information and assessing needs. Infants and Young Children, 22(3), 224-233.

Minnes P. \& Nachshen J. S. (1997) The family stress and support questionnaire: a focus on the needs of parents. Journal on Developmental Disabilities 5, 67-76.

Moos, R. H. (1974). Family environment scale. Palo Alto: Consulting Psychologists Press. Morgan, S. B. (1988). The autistic child and family functioning: A developmental-family 
systems perspective. Journal of Autism and Developmental Disorders, 18(2), 263-280.

Nachshen, J. S., Woodford, L., \& Minnes, P. (2003). The family stress and coping interview for families of individuals with developmental disabilities: A lifespan perspective on family adjustment. Journal of Intellectual Disability Research, 47(4/5), 285-290.

Oliver, M. (2009). Understanding disability: From theory to practice. UK: Palgrave Macmillan.

Olson D. H., Sprenkle D. H. \& Russell C. (1979) Circumplex Model of Marital and Family Systems: cohesion and adaptability dimensions, family types, and clinical applications. Family Process, 18, 3-28.

Oosterling, I., Visser, J., Swinkels, S., Rommelse, N., Donders, R., Woudenberg, T., Roos, S... Buitelaar, J. (2010). Randomized controlled trial of the focus parent training for toddlers with autism: 1-year outcome. Journal of Autism and Developmental Disabilities, 40, 14471458.

Patterson, S. Y., \& Smith, V. (2011). The experience of parents of toddlers diagnosed with autism spectrum disorder in the more than words parent education program. Infants and Young Children, 24(4), 329-343.

Qu, S. Q., \& Dumay, J. (2011). The qualitative research interview. Qualitative Research in Accounting and Management, 8(3), 238-264.

Raspa, M., Bailey, D. B., Olmsted, M. G., Nelson, R., Robinson, N., Simpson, M. E., Guillen, C., Houts, R. (2010). Measuring family outcomes in early intervention: Findings from a large-scale assessment. Exceptional Children, 76(4), 496-510.

Reichow, B. (2012). Overview of meta-analyses on early intensive behavioural intervention for young children with autism spectrum disorders. Journal of Autism and Developmental Disorder, 42, 512-520. 
Richards, L., \& Morse, J. M. (2013). Read me first for a user's guide to qualitative methods (3rd ed.). Thousand Oaks, CA: Sage.

Roberts, J., Williams, K., Carter, M., Evans, D., Parmenter, T., Silove, N., Clark, T., Warren, A. (2011). A randomized controlled trial of two early intervention programs for young children with autism: Centre-based with parent program and home-based. Research in Autism Spectrum Disorders, 5, 1553-1566.

Sandelowski, M. (2000). Focus on research methods: Whatever happened to qualitative description? Research in Nursing and Health, 23, 334-340.

Sallows, G. O., \& Graupner, T. D. (2005). Intensive behavior treatment for children with autism: Four-year outcome and predictors. American Journal of Mental Retardation, 110, 417-438.

Schertz, H. H., \& Odom, S. L. (2007). Promoting joint attention in toddlers with autism: a parent-mediated developmental model. Journal of Autism and Developmental Disorders, $37,1562-1575$.

Siebers, T. (2008). Disability Theory. United States of America: University of Michigan Press.

Smith, I. M., Koegel, R. L., Koegel, L. K., Openden, D. A., Fossum, K. L., Bryson, S. E. (2010). Effectiveness of a novel community-based early intervention model for children with autistic spectrum disorder. American Association on Intellectual and Developmental Disabilities, 115(6), 504-523.

Starks, H. \& Brown Trinidad, S. (2007). Choose your method: A comparison of phenomenology, discourse analysis, and grounded theory. Qualitative Health Research, 17(10), 1372-1380.

Strauss, K., Vicari, S., Valeri, G., D’Elia, L., Arima, S., Fava, L. (2012). Parent inclusion in early intensive behavioural intervention: The influence of parental stress, parent treatment fidelity, and parent-mediated generalization of behaviour targets on child outcomes. 
Research in Developmental Disabilities, 33, 688-703.

Summers, J. A., Poston, D. J., Turnbull, A. P., Marquis, J., Hoffman, L., Mannan, H., \& Wang, M. (2005). Conceptualizing and measuring family quality of life. Journal of Intellectual Disability Research, 49(10), 777-783.

Turnbull, A. P., \& Turnbull, III, H. R. (1990). Families, professionals, and exceptionality: A special partnership. (2nd ed.) New York: MacMillan.

Turnbull, A. P., Summers, J. A., Lee, S-K., \& Kyzar, K. (2007). Conceptualization and measurement of family outcomes associated with families of individuals with intellectual disabilities. Mental Retardation and Developmental Disabilities Research Reviews, 13, 346-356.

Trainor, A. A., \& Graue, E. (2013). Reviewing Qualitative Research in the Social Sciences. New York, NY: Routledge.

Trudgeon, C., \& Carr, D. (2007). The impacts of home-based early behavioural intervention programmes on families of children with autism. Journal of Applied Research in Intellectual Disabilities, 20, 285-296.

Wang, M., Summers, J. A., Little, T., Turnbull, A., Poston, D., \& Mannan, H. (2006). Perspectives of fathers and mothers of children in early intervention programmes in assessing family quality of life. Journal of Intellectual Disability Research, 50(12), 977988.

Weisner, T. S. (2002). Ecocultural understanding of children's developmental pathways. Human Development, 45(4), 275-281.

White, J. M., \& Klein, D. M. (2002). Family Theories (2nd ed.). California: Sage Publications. White, S. W. (2011). Social skills training for children with asperger syndrome and high 
functioning autism. New York, NY: The Guilford Press.

Williams, K. R., \& Wishart, J. G. (2003). The son-rise program intervention for autism: An investigation into family experiences. Journal of Intellectual Disability Research, 47(4/5), 291-299.

Woodgate, R. L., Ateah, C., \& Secco, L. (2008). Living in a world of our own: The experience of parents who have a child with autism. Qualitative Health Research, 18(8), 1075-1083.

Zellman, G. L., \& Perlman, M. (2006). Parent involvement in child care settings: conceptual and measurement issues. Early Child Development and Care, 176 (5), 521-538.

Zuna, N. I., Turnbull, A., \& Summers, J. A. (2009). Family quality of life: Moving from measurement to application. Journal of Policy and Practice in Intellectual Disabilities, $6(1), 25-31$.

Zwaigenbaum, L., Bryson, S., Lord, C., Rogers, S., Carter, A., Carver, L., Chawarska, K... Yirmiya, N. (2009). Clinical assessment and management of toddlers with suspected autism spectrum disorder: Insights from studies of high-risk infants. Pediatrics, 123(5), 1383-1391. 


\title{
Blcorview
}

RESEARCH INSTITUTE

\section{RYERSONUNIVERSITY}

\author{
Appendix A: Invitation Letter
}

June 10, 2013

\section{Invitation to Participate in "Exploring the Lived Experience of the Social ABC's Parent-Mediated Intervention Study"}

My name is Melanie Fenwick. I am a Masters student in the Early Childhood Studies degree program at Ryerson University. I am contacting you to invite you to take part in a research project as a follow up to your participation in the Social ABC's study conducted at Holland Bloorview under the supervision of Dr. Jessica Brian. The project is called Exploring the Lived Experience of the Social ABC's Parent-Mediated Intervention Study. The research team at Holland Bloorview have sent this information to you on my behalf.

\section{What is this study about?}

This study is interested in learning about your experience in the Social ABC's intervention. Interventions that involve parent training and education have the potential to impact the entire family. To date, there is little research exploring the experience of parent-delivered interventions for toddlers with Autism Spectrum Disorder related concerns. This study aims to provide insight on family experiences in the Social ABCs intervention.

\section{Why am I writing to you?}

I am inviting you to participate in a one-on-one interview where you will be asked to share your experience of the Social ABC's intervention. The interview will take between 1-2 hours of your time in a location that is most convenient for you. The following are examples of questions that will be asked in the interview: Did the social ABC's experience make a difference in your family's life? If so, how? Did the social $A B C$ 's intervention help achieve your family's goals? Did the social ABC's experience change your view of the future for your family? It is possible that you may feel uncomfortable answering some of the questions or elaborating on some of the concepts established during the interview. You are free to refuse to answer any questions and/or stop the interview for any reason at any time. We may request permission to access information that was collected for the Social ABCs such as your date of birth, gender, socioeconomic status, and your child's date of birth and gender. If you would prefer not to share this information, you may refuse and this will not impact your participation. 
As a token of our appreciation for your participation and for sharing your experience in the social ABCs intervention with us, we will provide a $\$ 20$ gift card to your family.

This research is an assignment towards the completion of the requirements for the Masters of Arts in Early Childhood Studies degree program at Ryerson University.

Your decision to take part in the study will not affect your relationship with Holland Bloorview Kids Rehabilitation Hospital or Ryerson University.

Thank you very much for your time and consideration.

Sincere regards,

Melanie Fenwick, B.A.

melanie.fenwick@ryerson.ca

If you are interested in participating, please contact Melanie Fenwick at melanie.fenwick@ryerson.ca or 416-230-2902. 


\section{Appendix B: Recruitment Phone Script}

\section{Exploring the Lived Experience of the Social ABCs Parent-Mediated Intervention Study PHONE SCRIPT FOR RECRUITMENT}

Hello, it's__ calling from the Social ABCs study. How are you? I'm calling to follow up with you about an invitation letter we emailed/mailed you about a week ago regarding a research project that is being conducted as a follow up to your participation in the Social ABC's study conducted at Holland Bloorview under the supervision of Dr. Jessica Brian. The project is called Exploring the Lived Experience of the Social ABC's Parent-Mediated Intervention Study and it is being lead by Dr. Brian and her research student Melanie Fenwick.

The study is interested in learning about your experience in the Social ABC's intervention. Interventions that involve parent training and education have the potential to impact the entire family. To date, there is little research exploring the experience of parents who have been involved in parent-delivered interventions for toddlers with Autism Spectrum Disorder-related concerns. This study hopes to give us more information about how families experience the Social $\mathrm{ABCs}$ intervention.

I am calling you to invite you, on behalf of Melanie Fenwick, to participate in a one-on-one interview where you will be asked to share your experience of the Social ABC's intervention. The interview will take between 1-2 hours of your time in a location that is most convenient for you.

The types of question that you will be asked in the interview include: Did the social ABC's experience make a difference in your family's life? If so, how? Did the social ABC's intervention help achieve your family's goals? Did the social ABC's experience change your view of the future for your family? It is possible that you may feel uncomfortable answering some of the questions or elaborating on some of the concepts established during the interview. You are free to refuse to answer any questions and/or stop the interview for any reason at any time.

If you're interested or have any questions or concerns, please contact Melanie by email at melanie.fenwick@ryerson.ca or by calling her at 416-230-2902.

Thank you for taking the time to consider this opportunity! We really appreciate it. 


\section{Blcorview}

RESEARCH INSTITUTE

\section{RYERSONUNIVERSITY}

\section{Appendix C: Consent Form}

Title of Primary Research Study: "Social ABCs" for Toddlers with Suspected Autism:

Evaluation of a Parent-Mediated Intervention

Title of Sub-Study: Exploring the Lived Experience of the Social ABCs Parent-Mediated Intervention Study

\section{Investigators}

This is a graduate student-led research project with faculty supervision.

Graduate Student: Melanie Fenwick, B.A. Early Childhood Studies, Ryerson University

Bloorview Research Institute

Principal Investigator: Jessica Brian, PhD: Department of Pediatrics, University of

Toronto, Toronto, ON. Telephone: 416-425-6220 ext. 3410.

Dear Participant,

We would like to invite you to take part in a research study that is being offered as a follow up to your participation in the Social ABC's research study led by Jessica Brian at Holland Bloorview Kids Rehabilitation Hospital. Now that you have completed the Social ABC's parenttraining early intervention, we would like to explore your experience of the intervention for you and your family. There is minimal information available to tell us about family experiences of parent involvement in interventions for toddlers with Autism Spectrum Disorder related concerns. We are interested in exploring this topic. Your participation in this study is voluntary. Before you agree to take part in this study, it is important that you read the information below and ask questions before deciding whether or not to take part.

\section{What is the study about?}

The purpose of this study is to learn about your experience as a family having participated in the Social ABCs intervention group. Interventions that involve parent training and education can potentially impact the entire family. However, there is little research exploring this topic in autism specific interventions.

\section{Who will be involved in this study?}

All of the families in Toronto who have completed the Social ABCs intervention group will be invited to participate in this study. Depending on interest from families, we aim to include a minimum of seven families. Your family is being invited to participate and share your experience, and therefore one or both parents are invited to participate, if interested, to provide perspectives from all family members. 


\section{How will my my family and I be involved in this study?}

Melanie Fenwick will arrange a time to meet with you to conduct an interview. She will ask you questions about your experiences after taking part in the social ABCs intervention. The interview will take between 1-2 hours of your time in a location that is most convenient for you. This can take place at Holland Bloorview or in your home. The following are examples of questions that she will ask in the interview: Did the social ABC's experience make a difference in your family's life? If so, how? Did the social ABC's intervention help achieve your family's goals? Did the social ABC's experience change your view of the future for your family? She will audio record the interview. Later, the recording will be transcribed and analyzed along with the transcripts from other family interview. We will do this to look for themes that will help us to answer the research question.

We may request permission to access information that was collected for the Social ABCs study such as your date of birth, gender, socioeconomic status, and your child's date of birth and gender. If you would prefer not to share this information, this will not impact your participation.

\section{What are the risks and benefits?}

It is possible that you may feel uncomfortable answering some of the questions or elaborating on some of the concepts established during the interview. You are free to refuse to answer any questions and/or stop the interview for any reason at any time. Additionally, you have the right to withdraw from the study altogether, and the audio-recordings and transcripts will be destroyed. If this happens, we will not include them in the analysis. Please note your audio recordings and data can be removed up to July 1, 2013, after which withdrawal participation is not possible as the study will be complete.

We cannot be sure that you will receive any personal benefits from participating in this study. However, it is hoped that your participation will provide insight into family experiences of the social ABCs intervention for toddlers with Autism Spectrum Disorder related concerns. As a token of our appreciation for your participation and for sharing your experience in the social ABCs intervention with us, we will provide a $\$ 20$ gift card to your family.

\section{Will anyone know what I say and do?}

We will not record information that might identify you. Pseudonyms will be used to ensure confidentiality. Quotations from the interview may be used in the report; however no names or identifying information will be used. Only research team members will have access to the recorded interviews. We will destroy the audio recordings immediately after transcribing and checking the accuracy of the transcriptions. The transcription will not contain information that could be used to identify you or your family. They will be stored on encrypted and password protected data keys for transportation, and then on password protected computers. They will be stored for seven years after completion of the study before being destroyed. This is the policy at Holland Bloorview for research.

\section{Will this information be shared with anyone?}

The findings of the study may be reported in publications, but no identifying information will be included. It will be presented to Ryerson University in partial fulfillment of the requirements for the degree of Master of Arts in the program of Early Childhood Studies. Participating organizations (Holland Bloorview Kids Rehabilitation Hospital) will be provided with a summary of the findings. We will also send you a summary of what we learned. If the results of 
this study are published, your name will not be used and no information that discloses your identity will be released or published without your specific consent.

\section{Do I have to do this?}

Participation in this study is voluntary. Your choice of whether or not to participate will not influence your future relations with Ryerson University or Holland Bloorview Kids Rehabilitation Hopsital. If you decide to participate, you are free to withdraw your consent and to stop your participation at any time without penalty. At any particular point in the study, you may refuse to answer any particular question or stop participation altogether.

\section{What if I have questions?}

If you have any questions about the research now, please ask. If you have questions later about the research, you may contact.

\section{Researcher:}

Faculty Supervisor:
Melanie Fenwick

melanie.fenwick@ryerson.ca

Dr. Jessica Brian

416-425-6220 ext. 3410

If you have questions regarding your rights as a human subject and participant in this study, you may contact the Ryerson University Research Ethics Board (REB) for information.

REB Coordinator: Toni Fletcher

$$
\begin{aligned}
& \text { toni.fletcher@ryerson.ca } \\
& \text { Research Ethics Board } \\
& \text { Ryerson University } \\
& 350 \text { Victoria Street } \\
& \text { Toronto, ON M5B 2K3 } \\
& \text { 416-979-5042 }
\end{aligned}
$$

You may also contact the Holland Bloorview Research Ethics Board at 416-425-6220 ext. 3507 about your rights as a research participant.

Thank you for thinking about helping us with this project.

Yours truly,

Melanie Fenwick, B.A.

Graduate Student

Ryerson University

melanie.fenwick@ryerson.ca

416-230-2902
Jessica Brian, Ph.D. C. Psych

Psychologist and Clinician Investigator

Holland Bloorview Kids Rehabilitation Hospital

jbrian@hollandbloorview.ca

416-425-6220 x3410 


\section{Blcorview}

RESEARCH INSTITUTE

\section{RYERSONUNIVERSITY}

\section{CONSENT FORM}

\section{Title of Research Study: Exploring the Lived Experience of the Social ABCs Parent- Mediated Intervention Study}

Your signature below indicates that you have read the information in this agreement and have had a chance to ask any questions you have about the study. Your signature also indicates that you agree to be in the study and have been told that you can change your mind and withdraw your consent to participate at any time. You have been given a copy of this agreement. You have been told that by signing this consent agreement you are not giving up any of your legal rights.

Name of Participant (please print)

Signature of Participant

Date

Signature of Investigator

Date

\section{Audiotape Recording Agreement}

Your signature below indicates that you are aware that this interview will be audio-recorded and verbatim transcriptions will be later made from the audio-recording. No identifying information will be attached to the recording.

Signature of Participant

Date

Signature of Investigator

Date

Once the study is complete, I am happy to provide you with a summary of the findings, should you be interested. If so, please sign below.

Signature of Participant

Date

Preferred Contact Information 


\section{Appendix D: Interview Questions}

1. Tell me a little about your child. Tell me about your social ABC's experience.

2. Did the social ABC's experience make a difference in your child's life? If so, how?

a. PROBE 1: Did it have an effect on your child's development, behavior, and/or learning?

3. Did the social ABC's experience make a difference in your family's life? If so, how?

a. PROBE 2: Stress: Did your family experience changes in stress related to your child's disability (or other term as defined by parent in \#1) during or after the social ABCs intervention? If changes in stress have occurred, why?

i. What keeps you up at night? Has the social ABCs experience changed that?

b. PROBE 3: Family Functioning/Adaptability: Have there been changes in the relationships within your family while participating or since participating in the social $\mathrm{ABCs}$ intervention? For example, in areas of communication, closeness, family roles, or support between...

i. The child and the parent trained in social ABCs intervention

ii. Both parents (or the two caregivers of the child)

iii. Parents (or caregivers) and their other children

c. PROBE 4: Accommodation: Has the social ABCs intervention affected your daily routines as a family? If changes occurred, did they work for your family?

4. What were your family goals before beginning the social ABC's intervention? Did the social ABC's intervention help achieve your family's goals?

5. Did the social ABC's experience change your view of the future for your child and/or your family? 